\title{
Mario Vargas Llosa oder die mediale Kompetenz
}

Wir kommen nun wie versprochen in unserer Vorlesung zu einem Thema, das für die Postmoderne in einer sich während der zurückliegenden Jahrzehnte rasant verändernden Medienlandschaft von enormer Bedeutung war. Bereits bei Jorge Luis Borges waren wir auf die Frage medialer Kompetenz im Verhalten des argentinischen Autors vor Fernsehkameras und bei Rundfunkinterviews gestoßen und hatten gesehen, welch große Wirkung Borges als Vermarkter von Borges zukam. Auch auf diesem Gebiet war der Argentinier sicherlich ein Vorläufer.

Doch wir benötigen von der Textualität der Literatur her zumindest noch einen Anstoß, um zu verstehen, wie wichtig die Beherrschung der Medien-Klaviatur für Schriftsteller^innen zumindest seit der zweiten Hälfte des 20. Jahrhunderts national wie international geworden ist. Zu diesem Zweck müssen wir noch einmal einige Jahrzehnte zurückspringen, um diese Entwicklung lange vor der nun vorherrschenden Massivität elektronischer Medien einzufangen. Denn wir wollen anhand eines literarischen Beispiels bereits zu einem frühen Zeitpunkt verstehen, welch unerhörte Bedeutung gerade medialer Kompetenz bei Autor`innen der Literaturen im Zeichen der Postmoderne zukommt.

Bevor wir uns in der Folge mit dem wohl meist- und höchstausgezeichneten Literaten Lateinamerikas und vielleicht sogar der Literaturen der Welt beschäftigen, sollten wir uns - wie stets - in aller gebotenen Kürze einen Überblick über einige Biographeme dieses außerordentlich erfolgreichen sowie extrem fleißigen und talentierten peruanischen Schriftstellers vor Augen halten. Ich selbst hatte einmal das Vergnügen, auf ihn die Eloge für eine Ehrendoktorwürde an der Humboldt-Universität zu Berlin zu halten, bei der ich damals bereits feststellte, dass es für ihn die sechsunddreißigste Ehrendoktorwürde auf diesem Planeten war ...

Jorge Mario Pedro Vargas Llosa wurde am 28. März 1936 als einziger Sohn einer wohlhabenden Familie in Arequipa geboren, der zweitgrößten Stadt seines Heimatlandes Peru. Seit 1993 besitzt er die spanische Staatsbürgerschaft und ist 2011 - also ein Jahr nach dem Erhalt des Literaturnobelpreises für sein literarisches Werk - zum „Marqués de Vargas Llosa“ ernannt worden. Sie sehen, Sie haben es wirklich mit einer ganz besonderen Schriftstellerkarriere und -persönlichkeit zu tun!

Nichts aber scheint zu Beginn seines Lebens eine solche anzudeuten. Infolge der Trennung seiner Eltern unmittelbar vor seiner Geburt verbrachte der junge Vargas Llosa seine Kindheit im Haus der Großeltern mütterlicherseits im bolivianischen Cochabamba, wo er am katholischen Colegio La Salle die Grundschule absolvierte. In den Jahren 1945 und 1946 lebte er mit seiner Mutter und den Großeltern in Piura, inmitten einer Sandwüste am Rande der Anden im nördlichen Peru. Später versöhnten sich seine Eltern wieder und zogen mit ihrem Sohn nach 


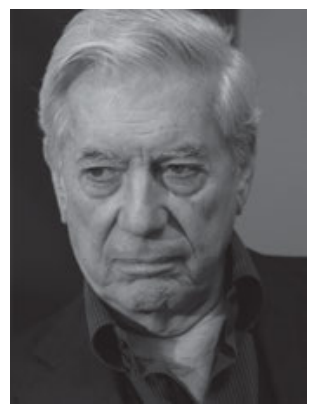

Abb. 125: Mario Vargas Llosa (Arequipa, Peru, 1936).

Lima, wo Mario Vargas Llosa auf Betreiben seines harten und von ihm ungeliebten Vaters, der seine Mutter schlug, ab 1950 an der Kadettenanstalt Leoncio Prado eine zweijährige Schulzeit absolvierte, die er später in Piura abschloss. Wie schon in Lima, arbeitete er auch hier bei einer Lokalzeitung und brachte sein erstes Theaterstück zur Aufführung. Der Vater hatte ihm mit Hilfe der Kadettenanstalt die Schriftstellerei austreiben wollen; doch er erreichte das Gegenteil, denn nach eigenem Geständnis wurde sein Sohn gerade dort endgültig zum Schriftsteller. Und die Kadettenanstalt zur literarischen Zielscheibe.

Ab 1953 studierte er an der Universität San Marcos in Lima Jura sowie Literatur und übte unterschiedliche Nebentätigkeiten zur Finanzierung seines doppelten Studiums aus. Er widmete sich immer mehr dem Schreiben und schloss sein Literaturstudium ab. 1954 heiratete er Julia Urquidi, seine zwölf Jahre ältere Tante, was in der Familie einen Skandal auslöste. Wir werden uns gleich mit einem Roman beschäftigen, in welchem der Schriftsteller seine Beziehung fiktionalisierte, was zu weiteren Skandalen und einem endgültigen Streit mit seinem Vater führte, der ihm vorwarf, im Roman negativ dargestellt worden zu sein. Gleich also zu La tía Julia y el escribidor, zu Tante Julia und der Kunstschreiber, wobei wir auch einen kleinen Seitenblick auf dessen autobiographische Facetten werfen!

Dank eines Stipendiums konnte Vargas Llosa ab 1959 an der Universidad Complutense promovieren und veröffentlichte erste literarische Texte. Das literaturwissenschaftliche Studium, das ihn letztlich in einen Poeta doctus verwandelte, blieb auch später ein treuer Begleiter des Schriftstellers, verfasste er doch immer wieder ausgedehnte kritische Buchpublikationen zu Gabriel García Márquez, Gustave Flaubert, Victor Hugo oder andere Autoren wie Arguedas oder Onetti. Ebenfalls 1959 erhielt er von der französischen Zeitschrift Revue Française als Preis für eine Erzählung aus seiner Kurzgeschichtensammlung Die Anführer (Los jefes) eine Einladung nach Paris. Vargas Llosa verlagerte seinen Lebensmittelpunkt nach Europa und lebte seit dieser Zeit überwiegend in Paris, Barcelona, Madrid und London. Mit seinem Debütroman La ciudad y los perros (Die Stadt und die Hunde) erlangte er internationales Renommee; das Buch, dessen Hand- 
lung Geschehnisse in einer Kadettenanstalt anprangert, wurde in Lima öffentlich verbrannt und sorgte auch sonst für Aufsehen. Es ist auffällig, welch schlechte Presse der peruanische Autor immer wieder in seinem Heimatland hatte. Die militärischen Hüter der Kadettenanstalt freilich wussten, warum sie - was sicherlich unentschuldbar ist - den Roman öffentlich verbrannten.

Nach der Scheidung von Julia Urquidi blieb Vargas Llosa in der Familie und heiratete 1965 seine Cousine Patricia Llosa, die er an der Pariser Sorbonne kennengelernt hatte und mit der er drei Kinder hat. Patricia regelte in den folgenden Jahrzehnten alles für ihn, wurde seine Managerin und hielt ihm den Rücken frei, so dass sich „der schöne Mario“, wie ihn manche nennen, ganz der Schriftstellerei widmen konnte. Als Journalist arbeitete er für France Télévision und die Nachrichtenagentur AFP, so dass er an seine journalistischen Erfahrungen anknüpfen und seine medialen Kompetenzen vergrößern konnte. Später zog die Familie nach London und Barcelona.

Sein im Jahr 1966 erschienener Roman La casa verde erhielt den angesehenen Rómulo-Gallego-Preis, anlässlich dessen der junge Autor in seiner Dankesrede ein glühendes Bekenntnis für den Sozialismus ablegte. Doch sollte ihm dies später noch bitter aufstoßen. Denn in der Folge kam es bezüglich seiner politischen Haltung gegenüber der Kubanischen Revolution zu Differenzen mit ehemaligen Weggefährten wie Gabriel García Márquez, über dessen Werk Vargas Llosa 1971 in Madrid mit Historia de un deicidio promovierte, und ab Ende der sechziger Jahre zur politischen ,Wasserscheide“ im Kontext der sogenannten Padilla-Affäre. Die meisten lateinamerikanischen „Boom“-Autoren bekannten sich zur Kubanischen Revolution, Vargas Llosa aber entschied sich dagegen und prangerte in einem offenen Brief, der von zahlreichen Intellektuellen unterzeichnet wurde, die Verfolgungen und Inhaftierungen von Schriftstellern auf Kuba an. Er orientierte sich politisch zunehmend an einem liberal-konservativen Modell und geriet in Konflikt mit den meist linksliberalen lateinamerikanischen Autor^innen.

Für den Schriftsteller Vargas Llosa bedeutete La casa verde - ein komplex verwobener Roman mit geschickt kombinierten Schauplätzen in verschiedenen Landesteilen Perus - den endgültigen Durchbruch. Mit großer Regelmäßigkeit erschienen Romane und folgten Auszeichnungen, welche hier nicht aufzuzählen sind. Von 1976 bis 1979 war Vargas Llosa Vorsitzender des internationalen PenClubs. 1977 wurde er Mitglied der Peruanischen Akademie für Sprache, später auch Mitglied der Real Academia Española de la Lengua.

In den achtziger Jahren hielt er sich häufiger in Peru auf und nahm regen Anteil am politischen Leben des Landes; so etwa 1983 als Mitglied einer Regierungskommission zur Aufklärung von Morden an Journalisten. 1988 gründete er als Vorsitzender des liberalen „Movimiento Libertad“ zusammen mit konservativen Politikern den „Frente Democrático“. Als gemeinsamer Präsidentschafts- 
kandidat der liberalen politischen Rechten unterlag er bei den Wahlen von 1990 dem Überraschungssieger Alberto Fujimori, dessen Regierungszeit freilich im Zeichen von Korruption und Autoritarismus stand. Vargas Llosas Wandlung vom Sozialisten und kritischen Linken, der er in den sechziger Jahren gewesen war, zum Neoliberalen und Konservativen vermochte letztlich angesichts mangelnder Volksnähe und der geplanten, von Privatisierungen gekennzeichneten Wirtschaftspolitik nicht zu überzeugen, zumal seine Gegner ihm die Sache mit der Kadettenanstalt und manche erotischen Schriften zur Last legten.

Mario Vargas Llosa kehrte Peru wieder den Rücken, nahm die spanische Staatsbürgerschaft an und betätigte sich verstärkt als Schriftsteller. Er vergaß neben der Fiktion jedoch nie, literaturwissenschaftliche Bücher $\mathrm{zu}$ veröffentlichen, politische Kolumnen zu verfassen, die literarischen Feuilletons verschiedenster Zeitschriften zu bedienen und auch Fernsehsendungen $\mathrm{zu}$ moderieren. War sein erstes literarisches Zeugnis ein Theaterstück gewesen, so wandte er sich nun wieder stärker dem Theater zu und brillierte schließlich auch als Schauspieler in eigenen Stücken. Doch das Rückgrat seiner literarischen Arbeit bildeten seine Romane, die auch weiterhin sehr regelmäßig erschienen. Die Liste seiner literarischen Auszeichnungen ist beeindruckend und schließt den Príncipe de Asturias-Preis (1986), den Premio Planeta (1993), den Premio Cervantes (1994), den Jerusalem-Preis (1995) sowie 1996 den Friedenspreis des Deutschen Buchhandels mit ein, bevor ihm nach vielen weiteren Auszeichnungen 2010 als Höhepunkt seiner Karriere der Literaturnobelpreis zuteilwurde. Im Jahr 2015 ließ er sich von seiner jahrzehntelangen Weggefährten, Managerin und Ehefrau Patricia scheiden und heiratete das philippinisch-spanische Ex-Model Isabel Preysler, 1951 geboren, spanienweit bekannt als Journalistin der Zeitschrift $i$ Hola! und vor allem als Ehefrau von Julio Iglesias. Dieses Faktum an sich war bemerkenswert: Bei Vargas Llosas dritter handelte es sich um die erste Heirat außerhalb seiner Familie. Schlagzeilen machte freilich auch sie!

Betrachten wir sein gesamtes literarisches Oeuvre, so ist es faszinierend $\mathrm{zu}$ sehen, wie konsequent Mario Vargas Llosa die Romandiegesen seiner Erzählprosa ausweitete. Spielten die ersten Erzählungen und Romane vorwiegend in einem Viertel von Lima, in Miraflores, so umfasste er mit La casa verde 1966 das gesamte Territorium Perus und verlagerte mit La guerra del fin del mundo 1981 seinen Romanschauplatz - für einen spanischsprachigen Lateinamerikaner überraschend - nach Brasilien. Danach verlegte er seine Romanhandlungen mit $\mathrm{La}$ fiesta del chivo über den dominikanischen Diktator Trujillo im Jahr 2000 in die Karibik, mit El paraíso en la otra esquina 2003 nach Paris und in den Südpazifik, mit den Travesuras de la niña mala 2006 weltweit auch auf den asiatischen Kontinent und mit El sueño del celta 2010 unter anderem nach Afrika, in den damals belgischen Kongo. 
Ich verbrachte zum damaligen Zeitpunkt auf Einladung seines spanischen Verlages eine knappe Woche mit diesem Schriftsteller. Er kam gerade erschöpft, aber bestens gelaunt von seinen Recherchen im Kongo zurück, um jeden Morgen, wie es seit langen Jahrzehnten seine Gewohnheit ist, früh aufzustehen, vor dem Frühstück zu schreiben und danach neugierig wie ein Kind - wir waren damals in einem spanischen Kloster - alle über alles zu befragen. Ich war beeindruckt, mit welcher Disziplin dieser Autor seinen Tagesablauf kontrollierte und einteilte. Tun Sie dies ein Leben lang, dann kommt ein gewaltiges Oeuvre zusammen! Wie für Gustave Flaubert ist das schreiben für Mario Vargas Llosa eine ungeheure Arbeit und Anstrengung, vor allem aber eine „ewige Orgie“, eine „orgía perpetua“, wie der promovierte Literaturwissenschaftler immer wieder betonte. Schreiben - so meinte er damals - werde er bis an sein Lebensende.

Wenden wir uns nun aber zunächst den siebziger Jahren und La tía Julia y el escribidor zu und damit einem Erzähltext, der 1977 zu einem Zeitpunkt erschien, als Mario Vargas Llosa längst zu den international bekanntesten Vertretern des neuen lateinamerikanischen Romans zählte und als Hauptvertreter des Boom der lateinamerikanischen Literaturen galt. ${ }^{1}$ Wie alle Romane, die vor diesem Text erschienen, ist auch letzterer in Peru angesiedelt. Und wie viele andere ist auch dieser Roman autobiographisch eingefärbt, man könnte sogar sagen, dass es sich bei ihm um eine letztlich autobiographisch strukturierte Erzählprosa handelt, also eine Art friktionalen Text, der ,Dichtung' und ,Wahrheit' miteinander verbindet.

Denn immerhin haben von den drei herausragenden Protagonisten des Romans nach dessen Publikation zweie gegen sein Erscheinen protestiert. Zum einen ein Bolivianer, den Vargas Llosa einst in Lima bei Radio Panamericana kennengelernt hatte, und der sich ebenso ungerecht behandelt fühlte wie Julia Urquidi, die erste Frau und vormals Tante Vargas Llosas, die später ihre Sicht der Dinge in einem Buch mit dem schönen Titel Lo que no dijo Varguitas veröffentlichte. Den Dritten im Bunde, Vargas Llosas Vater, hatte ich schon erwähnt. Ein vierter Protagonist des Romans nun war just jener „Varguitas“, von dem hier die Rede ist, und geklagt hat er gegen die Veröffentlichung des Romans deshalb nicht, weil er wohl einiges - wenn auch nicht alles - gemein hat mit jenem Mann, der auf dem Titelblatt als realer Autor erscheint: Mario Vargas Llosa. Sie sehen, die Dinge sind nicht ganz einfach, und genau darum auch spannend!

1 Vgl. Müller, Gesine: Die Boom-Autoren heute: García Márquez, Fuentes, Vargas Llosa, Donoso und ihr Abschied von den großen identitätsstiftenden Entwürfen. Frankfurt am Main: Vervuert 2004. 
Der in zwanzig Kapitel eingeteilte Roman beschäftigt sich auf zentrale Weise mit den Bedingungen und Gesetzlichkeiten des Schreibens selbst, ist also in hohem Maße selbstreflexiv. Damit haben wir schon gleich zu Beginn neben der autobiographischen Dimension eine zweite Ebene der Selbstreflexivität und vielleicht mehr noch Metatextualität ausgemacht, die diesem Roman die besondere Würze gibt. So konnte zurecht gesagt werden, dass die Handlung des Romans hinter den metafiktionalen Gehalt des Textes zurücktritt, wobei sich das Werk dennoch auf mimetischer Ebene lesen lasse. In den Kapiteln gerader Zahl werden - abgesehen vom letzten - voneinander unabhängige, in sich geschlossene Sex-and-Crime-Geschichten erzählt, eine Schreibweise, mit deren Verwoben-Sein der peruanische Autor erstmals in La casa verde erfolgreich experimentiert hatte.

Breiten Raum nimmt dabei die literarische Ausgestaltung des lateinamerikanischen „Radioteatro“ ein, das innerhalb populärer Distributionen kultureller Artefakte in den Ländern Lateinamerikas eine Spitzenstellung einnimmt. Sie können dies noch heute bei einem Besuch in Lateinamerika leicht konstatieren: Es behauptet seine starke Stellung auch gegenüber den US-dominierten elektronischen Medien, für die man elektronische Bildschirme und ein mehr oder minder ständiges Hinschauen braucht. Das ist bei einem Radiogerät - sozusagen einem Kofferradio, wie man das früher nannte - nicht notwendig. Es handelt sich dabei durchaus um ein lateinamerikanisches Spezifikum, denn wenn beispielsweise auf dem Campus am Neuen Palais sauber gemacht wird, laufen auch Radiogeräte, aber diese bringen keine Radioteatros, sondern dudeln die übliche Musik. Noch ist es in Lateinamerika den großen und zunehmend ausländisch dominierten digitalen Medien also nicht gelungen, diesen medialen Rivalen auszuschalten.

Vielleicht sollten wir aber eher von „Radionovela“ als von „Radioteatro“ sprechen, denn wir haben es ja mit der literarisch-narrativen Behandlung einer populären Erzählform zu tun. Es handelt sich um Zeugnisse einer Massenkultur, welche sich im lateinamerikanischen Roman erstmals während der dritten Phase beschleunigter Globalisierung bemerkbar machte, als José Martí etwa über Vorformen dessen berichtete, was man viel später als US-amerikanische Western bezeichnete. Damals galoppierten freilich nicht berittene Cowboys über eine Leinwand, sondern Männer mit Pferd und Schießeisen in einer eigens dafür erstellten Arena - und sie zogen die Massen an.

Bei diesen Radionovelas, die uns Mario Vargas Llosa in La tía Julia y el escribidor kredenzt, mag es sich um verworrene, bisweilen sogar ,hirnverbrannte‘ Narrative handeln - wie oftmals gesagt wurde -, die ihre eigentliche Kraft aus der Verbindung mit den Handlungssträngen des Romans bezögen. Ich finde freilich, dass dieses Schreiben im Modus dessen, was man auf Spanisch als „cursi“ bezeichnet, 
sehr wohl einen eigenen literarischen Reiz besitzt und nicht einfach als ,unliterarisch` ausgegrenzt werden kann. Denn es ging dem peruanischen Schriftsteller darum, diese massenkulturellen Phänomene in ihrer Genese und Verfertigung in den Ablauf seines Romans einzubauen. Und jene Geschichten sind mit einer kräftigen Dosis Humor und Selbstironie à la Vargas Llosa gewürzt - denn nicht umsonst mag ihm präsent gewesen sein, dass seine ersten Theaterstücke (wie Die Flucht des Inka) und literarischen Versuche stark von derartigen Formen geprägt waren.

Ich möchte mich an dieser Stelle ein wenig aus dem Fenster lehnen: Die einzelnen Texte haben sehr wohl eine nicht nur romaninterne Funktion, sondern besitzen auch ihre eigene literarische Qualität, die sich nicht in einer Hilfs-Funktion erschöpft. Das Element von Konstruktion und Konstruiertheit, also der stark ,gezimmerte“ Charakter des Textes, erinnert uns - wenn wir an den vergangenen Vorlesungszyklus zum Thema LiebeLesen denken² - an einen so konstruktivistischen Roman wie Calvinos Se una notte d'inverno un viaggiatore. Die Kapitel ungerader Zahl jedenfalls treiben gleichsam die Handlung des Romans an sich voran.

Im zwanzigsten und letzten Kapitel scheint sich das erzählende Ich als der gereifte und gefestigte Autor Mario Vargas Llosa zu erkennen zu geben, doch sollten wir uns vor derlei uns mittlerweile altbekannten literarischen Verfahren hüten. Denn natürlich handelt es sich auch hier nicht um den realen Autor von Fleisch und Blut, sondern wiederum um eine weitere, autobiographisch eingefärbte Romanfigur, welche das Element des autobiographischen Erzählens erzähltechnisch vollendet mit dem Auseinandertreten zwischen erzählendem Ich und erzähltem Ich. Dabei lässt sich eine erzähltechnische Bewegung stetiger Annäherung beider Ebenen feststellen.

Jedenfalls wird sich das erlebende Ich als achtzehnjähriger Marito oder Varguitas seiner Berufung zum Schriftsteller bewusst. Die autobiographische Fiktion setzt sich fort, indem die Heirat mit seiner um vierzehn Jahre älteren und mittlerweile glücklich geschiedenen Tante Julia in den narrativen Fokus rückt. Interessant ist dabei, dass die eigentliche Geschichte strikt linear erzählt wird, erzähltechnisch also keine größeren experimentellen Risiken eingegangen werden. Dabei ist Pedro Camacho im Grunde die zentrale poetologische Figur, welche die verschiedenen Ebenen des Romans miteinanderverknüpft. Denn er hat sich mit seiner Arbeit als Künstler und Schauspieler - das heißt konkret als Verfasser von Radionovelas und gleichzeitig als deren Interpret - ganz der Arbeit an der Kunst verschrieben und wird damit zur großen künstlerischen Heraus-

2 Vgl. Ette, Ottmar: LiebeLesen (2020), S. 33-59. 
forderung für den noch jungen, ungelenken und überdies in Liebesdingen gänzlich unerfahrenen Varguitas. Dass ersterer die große komische Figur des Romans sei, wie oft zu hören ist, darf mit guten Gründen bestritten werden, portraitierte sich Mario Vargas Llosa doch in Teilen dieser Figur mit allzu großer Ernsthaftigkeit.

Die unerschöpflich kreative Energie des Vielschreibers Camacho wird in jedem Falle zum Vorbild für den Möchtegern-Schriftsteller Varguitas, der ähnlich wie Mario Vargas Llosas großes Vorbild Gustave Flaubert am Tag kaum etwas zu Papier bringt und gleichsam um jede Zeile kämpfen muss. Schreiben bedeutet für ihn eine große Anstrengung, welcher er nur - wie einst Flaubert - dank eiserner Disziplin Herr werden kann. Wir sehen, auf welch geschickte Weise in diese Konstellationen autobiographische Befindlichkeiten des Schreibenden selbstreflexiv in den Roman eingearbeitet sind.

Im Gegensatz hierzu findet Pedro Camacho nicht einmal mehr die Zeit, seine eigenen Blätter zumindest kurz zu überfliegen, geschweige denn zu korrigieren. Er ist gleichsam der Balzac unter diesen Autoren, immer im Zugzwang und immer vorangetrieben von Zwängen der Abgabe, aber zugleich immer fruchtbar in seiner Imagination wie seiner Gabe geschickten Schreibens. Ihm fällt alles leicht, doch dieses Schreiben ist ein Schreiben gegen die Uhr. Mit dem Voranschreiten der Arbeitswut Pedro Camachos, mehr aber noch mit seinem schrittweisen Zusammenbruch, erschließt sich im Roman immer deutlicher eine metafiktionale Ebene, die freilich erst am Ende des Romans abschließend und eindrucksvoll entfaltet wird.

Denn erst aus der Perspektive des erfolgreichen, aus dem Ausland vorübergehend nach Peru zurückgekehrten Schriftstellers wird im Nachklapp deutlich, dass die unterschiedlichen Protagonisten der Romandiegese zumeist Schiffbruch erlitten haben. Vor allem Pedro Camacho ist buchstäblich ,auf den Hund gekommen'. Dabei zeigt sich, dass seine Geschichten auf der eigenen Biographie beruhten, so dass sich bereits auf dieser Ebene eine deutliche metafiktionale Beziehung zum Roman La tía Julia y el escribidor ergibt. Scheitert Pedro Camacho wirklich an der Produktion von schlichtem Kitsch, in dem, was auf Spanisch als „cursi“ oder „cursilería“ bezeichnet wird? Ist ein Schreiben also zum Scheitern verurteilt, weil es sich gleichsam ohne Distanz zum eigenen Leben vollzieht? Dies scheint mir doch eine offene Frage zu sein.

Denn immerhin tritt dieses Scheitern erst dann ein, als die Flut sich gleichzeitig abspielender Radionovelas so sehr ansteigt, dass er sich nicht mehr vor Auftragsarbeiten retten kann und auch in seinem schreibbaren Erinnerungsvermögen hoffnungslos überspült wird. Dagegen sei Mario Vargas Llosa durch seine ironische Distanz zu sich selbst und seinem Stoff eine Geschichte auf hohem literarischem Niveau gelungen, so behauptet man häufig. Ich denke aber, dass 
die unterschiedlichen Schriftstellerfiguren und ihre verschiedenartigen Reaktionsweisen sehr viel stärker miteinander verwoben sind und sich nicht so einfach auftrennen lassen, wie dies in einer solchen Deutung geschieht. Wir erfahren in diesem Roman metafiktional viel von den Bedingungen eines Schreibens, welches der reale Autor nicht von außen amüsiert betrachtet, sondern in welches er selbst sehr stark verstrickt ist, weiß doch der promovierte Literaturwissenschaftler sehr wohl, welche literarischen Traditionen und damit verbundenen Schriftstellerfiguren in ihm gleichzeitig präsent sind. Denn Mario Vargas Llosa ist auch das: ein unglaublich disziplinierter Polygraph, bei dem die Vielschreiberei freilich zu immer wieder anderen und faszinierenden Büchern und Texten führte.

Übrigens ist der Roman selbst sehr leicht rezipierbar, was ihn nicht zuletzt zu seinem großen Erfolg verholfen oder zumindest dazu beigetragen hat. Ob es bei ihm wiederum zu einer Art Rückverwandlung in eine Radionovela kam, entzieht sich meiner Kenntnis, wäre aber sehr wohl denkbar, ja wünschenswert: Viele Romane des peruanischen Schriftstellers sind Vorlagen für Drehbücher zahlreicher Verfilmungen, von Radiohörspielen, Theaterstücken und vielen anderen kreativen Weiterverarbeitungen geworden. Jedenfalls scheint mir, dass in diesem unterhaltsamen Roman die Grenzlinie zwischen Trivialliteratur und hoher Literatur zwar gezogen, zugleich aber hinterfragt und sehr hintergründig unterlaufen wird. Im Kontext des „Great Divide“ ist La tía Julia y el escribidor ein Roman, der die traditionellen Mappings hinterfragt und das „Gap“ zwischen den unterschiedlichen, traditionell voneinander scharf getrennten Kunstbereichen $\mathrm{zu}$ überbrücken, in jedem Fall zu überspannen sucht. Die weltweite Auflagenhöhe von Vargas Llosas Romanen spricht dafür, dass dies nicht nur in der Theorie, sondern auch in der Praxis erfolgte. Für Deutschland lässt sich mit Blick auf sein angestammtes Verlagshaus Suhrkamp sagen, dass die hohen Erlöse seiner Romane wesentlich zur Finanzierung einer Vielzahl von Übersetzungen lateinamerikanischer Texte beitrugen, die wohl ohne diese Einnahmequelle niemals übersetzt worden wären.

Die autobiographische Dimension des Romans wird übrigens vom Autor schon paratextuell gestützt. Denn in dessen Titel taucht der Name Julia ebenso auf wie in der dortigen Widmung an eben Julia Urquidi, der - wie es heißt - ,ich und dieser Roman so viel verdanken“. Damit wird letztlich ein autobiographischer Pakt mit dem Lesepublikum geschlossen, ein Pakt, der im Gewühl verzwickter Ereignisse der Radionovelas zwar bisweilen untergeht, aber im Verlauf der einzelnen Kapitel bis hin zum letzten immer wieder erneuert wird. Die Selbst- und Metareflexivität der zweiten Ebene - also die des literarischen Diskurses - wird anhand des Mottos deutlich gemacht, das Salvador Elizondo und seinem Text El Grafógrafo entnommen ist. Es zitiert eine hübsche Passage, in welcher sich der Schreibende schreibend sieht, wie er schreibt, dass er sieht wie er schreibt und so 
weiter: Es sind Spiegelungen von Spiegelungen, ganz in dem Sinne, den Maurice Blanchot so früh im 20. Jahrhundert prospektiv für die kommende Literatur angesprochen und angekündigt hatte. Diese autobiographische Dimension tritt dann auf der fiktionalen Ebene im Text selbst bereits im Incipit hervor. Schauen wir uns daher den Beginn dieses ersten Kapitels an:

In dieser lang schon zurückliegenden Zeit war ich noch sehr jung und lebte mit meinen Großeltern in einem Landhaus mit weißen Wänden in der Ocharán-Straße im Stadtteil Miraflores. Ich studierte an der San Marcos-Universität Jura, glaube ich, und hatte mich mit dem Gedanken abgefunden, mir mein Leben später mit einem bürgerlichen Beruf zu verdienen, obwohl es mir im Grunde weitaus mehr entgegengekommen wäre, Schriftsteller zu sein. Ich hatte eine Arbeit mit einem pompösen Titel, bescheidenem Honorar, illegalen Aneignungen und einer elastischen Arbeitszeit: Informationsdirektor von Radio Panamericana. ${ }^{3}$

Wie Sie sehen, wird in diesem Zitat gleich von Beginn an die zeitliche Distanz zwischen einem erzählenden und einem erzählten Ich eingeführt, so wie dies in der Gattung Autobiographie traditionellerweise üblich ist. Die Geschichte wird gleichsam aus dem Rückblick auf eine Zeit erzählt, die als längst vergangen charakterisiert wird. Ganz im Sinne der Autobiographie und ihrer herkömmlichen Ausgestaltung befinden wir uns dann im letzten Kapitel auf jener Zeitstufe, von der aus die Zeit so distanziert schien, haben also jene Distanz durchschritten, an deren Ende wir dem Ich-Erzähler gleichsam beim Schreiben über die Schulter schauen können.

Wesentliche Handlungselemente des Romans werden hier bereits eingeführt, etwa das kleine schmucke Anwesen in einem recht schicken Viertel von Lima, wozu auch gleich die Möglichkeit eines Studiums tritt, dessen Ziel ein üblicher Beruf lateinamerikanischer Bürgersöhne ist: nämlich als Jurist oder Anwalt seine Brötchen zu verdienen. Alles ist eigentlich schon fertig, bevor das Leben richtig begonnen hat. Die fehlenden Eltern, von denen angesichts der Großeltern nicht die Rede ist, verweisen zugleich auf eine Problematik, die erst viel später im Roman thematisiert werden wird. Denn erst dann wird jener ungeliebte und hartherzige Vater auftreten, der mit seiner harschen Reaktion auf die Veröffentlichung des Buches noch ein allerletztes Mal ins Leben des Autors treten wird. Im Roman selbst freilich sehen wir eine Art Machtkampf zwischen Vater und Sohn, bei dem sich letzterer durchsetzt.

Zu guter Letzt wird im Zitat auch die sich andeutende Berufung zum Schriftsteller angeführt, welche jedoch erst vor dem Horizont eines nicht weiter beachteten Jurastudiums an der San Marcos-Universität in Lima erscheint. Am Ende des

3 Vargas Llosa, Mario: La tía Julia y el escribidor. Barcelona: Seix Barral 1977, S. 11. 
Zitats sehen wir den Arbeitsplatz des Ich-Erzählers bei Radio Panamericana, wo sich die gesamte künstlerische Dimension des nachfolgenden Textes mit seiner spielerischen Einbettung lateinamerikanischer Massenkultur situieren wird.

Damit tritt eine Dimension hinzu, die - so scheint mir - oftmals zu wenig beachtet wird, der wir uns aber unbedingt zuwenden sollten. Dabei geht es um die Beziehung und oftmals Konkurrenz zwischen verschiedenen künstlerisch-massenkulturellen Medien, genauer zwischen dem Reich der Literatur, dem erträumten Schriftsteller-Sein einerseits und andererseits dem Bereich der Massenkommunikation beziehungsweise Massenkultur in Form eines populären Radiosenders, mit dessen Hilfe - und dies wird im Roman immer wieder betont binnen kürzester Frist größte Menschenmassen erreicht werden können. Genau auf diesem Aspekt leichter Erreichbarkeit eines größeren Publikums liegt der Schwerpunkt des Romans: also nicht so sehr in der Konkurrenz zwischen Roman und Trivialroman, zwischen hoher und niederer Literatur, als vielmehr zwischen dem Medium Literatur einerseits mit seinen spezifischen Schreibbedingungen und dem Medium Rundfunk andererseits, das ebenfalls eine klare medienspezifische Vorgabe besitzt.

Aufschlussreich ist diese mediale und sinnliche Beziehung allemal, insofern ebenso im Bereich der Literatur, wo mit den Augen gelesen wird und Bilder beim Lesepublikum per Hypotypose erzeugt werden, als auch im Bereich des Hörfunks, wo die Augen im Sinne einer Erfassung von Bildern zugunsten der Ohren als dominantem Wahrnehmungssinn weitgehend ausgeschlossen sind, spezifische mediale Rezeptionsbedingungen erzeugt werden. Man könnte allerdings die Literatur sehr wohl auch dem Bereich des Hörens zuordnen, insofern ein Schriftbild diskursiv umgesetzt wird und die Rede dieses Diskurses gleichsam akustisch vernehmbar erscheint. Dies hat mit den verschiedenen Revolutionen des Lesens zu tun, auf die wir im Rahmen einer anderen Vorlesung zu sprechen kamen, ${ }^{4}$ und zeigt sich als Schwundstufe des lauten Lesens noch darin, dass wir etwa in der S-Bahn unsere Gegenüber des Öfteren beim Lesen der Zeitung die Lippen bewegen sehen.

Doch geht es bei dieser Konstellation nicht um die intermediale Transposition zwischen Bild und Text, wie sie in unserer Zeit so dominant geworden ist, sondern von Schrifttext zu Hörtext. Die Schauspieler der Radionovelas oder „Radioteatros “ werden nicht von ihren Zuschauern gesehen und besitzen oftmals Stimmen, die letztlich auf eine ganz andere Körperlichkeit verweisen als jene, die ihnen in Wirklichkeit zugeordnet ist. Sie kennen diesen Effekt aus dem bekannten Song Video Killed the Radio Star von The Buggles über die medialen Schwellen zwi-

4 Vgl. in der Reihe „Aula“ Ette, Ottmar: LiebeLesen (2020), S. 93-103. 
schen Stumm- und Hörfilm beziehungsweise Radio und Video. All dies hat mit Visualisierung und mehr noch Visibilisierung von Körpern zu tun. ${ }^{5}$

Wir erreichen damit einen Aspekt unserer Diskussion des Schreibens in der Postmoderne, der bislang weitgehend ausgeblendet blieb und oftmals $\mathrm{zu}$ wenig reflektiert wird: den der inter- und transmedialen Transposition im Medium der Literatur. Bei diesen Beziehungen geht es nicht allein um Visualisierung, um die Relationen zwischen Text und Bild - ein Forschungsgebiet, das überaus populär ist und seit langen Jahrzehnten vielfältige Forschungsarbeiten auf sich gezogen hat, so dass man mitunter den Eindruck einer ,Überforschung dieses Gebiets gewinnen kann. Bei der Beziehung, auf die ich abziele, scheint es sich auf den ersten Blick vielmehr um eine Art Verfremdung von Literatur zu handeln. Doch gehen diese inter- und transmedialen Relationen im Grunde zu den Anfängen unserer Literaturen zurück und weisen zugleich über diese hinaus: Ich spreche von den Beziehungen zwischen Literatur und Hören, zwischen Text und Ohr. Mit anderen Worten: „Attention au phonotexte“! ${ }^{6}$

Bereits die Arbeit des Ich-Erzählers bei Radio Panamericana besteht just in dieser Transposition: Er muss Nachrichten aus den gedruckten Zeitungen händisch mit der Schere ausschneiden, um sie dann radiotechnisch ,umzuschminken', damit sie im Radio mediengerecht eingesetzt werden können. Dies betrifft genau die Arbeit der Transposition zwischen verschiedenen Medien - und damit beschäftigt sich letztlich auch La tía Julia y el escribidor in ganz zentraler Weise. Die so mühsam mit Schere und Klebstoff erarbeiteten „Boletines“ werden dann stündlich ausgestrahlt, also direkt vermarktet, wobei es sich sozusagen um Informationen aus zweiter oder - denken wir an die Nachrichtenagenturen - aus dritter oder vierter Hand handelt. Wohl bekomms!

Radio Panamericana belegte das zweite Stockwerk und die Dachterrasse eines brandneuen Gebäudes und besaß bezüglich seines Personals, seiner Ambitionen und Programme ein gewisses ausländisches und snobistisches Flair mit einem Schuss Modernität, Jugendlichkeit und Aristokratie. Obwohl seine Radiosprecher keine Argentinier waren, so hätten sie es (hätte Pedro Camacho gesagt) verdient, welche zu sein. Man spielte viel Musik, massenhaft Jazz und Rock mit einem Spitzchen Klassik, der Sender strahlte als erster in Lima die neuesten Hits aus New York und Europa aus, doch verachtete man keineswegs lateinamerikanische Musik, solange sie ein Minimum an Komplexität besaß [...]. Radio Central hingegen

\footnotetext{
5 Vgl. zu dieser Differenz Ette, Ottmar / Müller, Gesine (Hg.): Visualisierung, Visibilisierung und Verschriftlichung. Schrift-Bilder und Bild-Schriften im Frankreich des 19. Jahrhunderts. Berlin: Verlag Walter Frey - edition tranvía 2015.

6 Vgl. zur Phonotextualität Ette, Ottmar: Dimensiones de la obra: iconotextualidad, fonotextualidad, intermedialidad. In: Spiller, Roland (Hg.): Culturas del Río de la Plata (1973-1995). Transgresión e intercambio. Frankfurt am Main: Vervuert Verlag 1995, S. 13-35.
} 


\begin{abstract}
drängelte sich in einem alten Haus voller Innenhöfe, Irrungen und Wirrungen zusammen, und es genügte, seine sorglosen und den lokalen Slang übertreibenden Radiosprecher zu hören, um augenblicklich deren Ausrichtung an einer breiten, plebejischen und höchst kreolischen Masse zu erfassen. Hier verbreitete man nur wenige Nachrichten, und hier war auch die peruanische Musik einschließlich der andinen die unangefochtene Herrscherin; und es war keineswegs selten, dass sich indianische Sänger aus Provinzbühnen an den für das Publikum offenen Sendungen beteiligten, welche bereits Stunden vorher an den Türen der Veranstaltungen ganze Massen von Leuten zusammenführten. Auch erbebten die Radiowellen dieses Senders häufig unter tropischer Musik, etwa aus Mexiko oder Buenos Aires, und die jeweiligen Programme waren einfach, einfallslos, effizient: Telefonwünsche, Geburtstagsständchen, der neueste Klatsch aus dem Showbusiness, Kitsch und Kino. Das Hauptgericht aber, das man stets von neuem und überreich auftischte, war das, was allen Umfragen zufolge die Einschaltquoten sicherte: die Radioteatros. ${ }^{7}$
\end{abstract}

Wir erkennen in dieser Passage auf wenigen Zeilen ein genau am Markt ausgerichtetes alternatives Programm für zwei Radiostationen, welches genau auf bestimmte Bedürfnisse der Hörerinnen und Hörer ausgerichtet ist. Man könnte hinter dieser Alternative marktwirtschaftliches Konkurrenzkalkül vermuten, was es im Grunde ja auch ist; doch beide Radiostationen gehören, was bei konkurrierenden Firmen nicht selten der Fall ist, demselben Besitzer. Es ist zweifellos so, dass Radio Central die nationalere Programmgestaltung besitzt, die ein Massenpublikum anzieht. Im Roman selbst heißt es dazu eher lakonisch, dass sich die beiden Radiostationen wie zwei tragische Schwestern ähnelten, von denen die eine voller Grazie, die andere aber von Geburt an voller Fehler und Mängel sei. ${ }^{8}$ In ihren Ausrichtungen stimmten beide in keiner Weise miteinander überein.

Nomen est omen: Während Radio Panamericana etwas „extranjerizante“ und snobistisch mit einem Hang zu internationaler Moderne funktioniert, wobei immer zuerst die großen Musikerfolge aus New York und Europa reproduziert werden, ist - im Gegensatz zu diesen internationalen und intellektuellen Ambitionen - Radio Central unverkennbar auf die breite Masse hin berechnet. Es zielt auf ein nationales Massenpublikum und betont das spezifisch regionale, kreolische Element. Hier zählt allein peruanische Musik unter Einschluss heimischer Klänge der andinen „Sierra“. Mit anspruchslosen Programmen und einfachen Informationen ausgestattet, präsentiert sich der Sender sehr wirkungsvoll und erfolgreich.

Für die hohen Einschaltquoten waren bei Radio Central, dies zeigten die Umfragen, die Radioteatros verantwortlich, von denen pro Tag mindestens ein

7 Vargas Llosa, Mario: La tía Julia y el escribidor, S. 12.

8 Ebda., S. 11f. 
halbes Dutzend ausgestrahlt wird. ${ }^{9}$ Gleich zu Beginn wird auf den Unterschied zwischen den jugendlichen, kristallinen Stimmen der Sprecher dieser Radioteatros und ihren alten Gesichtern aufmerksam gemacht. Dies ist ein für uns wichtiger Aspekt, erscheint die Stimme doch als ostentativer, manifester Beleg einer letztlich vom Leib abgetrennten Körperlichkeit (insofern der Körper mit seiner Stimme zu einem Objekt der Sprecherinnen und Sprecher wird, welche ihre Stimme wie einen separaten Gegenstand bearbeiten). Sobald sich das Fernsehen und damit die Visualisierung durchsetzt, so der Erzählerkommentar, wird diesen Menschen nichts anderes als der Selbstmord übrigbleiben: Video Killed the Radio Star.

Das Fernsehen wird sehr rasch zum Feind des Radios - doch wissen wir aus unserer historischen Erfahrung sehr präzise, dass sich nur die jeweiligen Zuständigkeitsbereiche wandeln, dass das Fernsehen aber keineswegs dem Radio den Todesstoß versetzen konnte. Damit wird gleich zu Beginn des Romans eine Konkurrenzsituation unterschiedlicher Medien eingeführt. Wieder ist der Erzählerkommentar im Roman sehr deutlich: Die Hausfrauen, die „amas de casa“, wären sicherlich sehr enttäuscht, wenn sie die Körper der Sprecherinnen und Sprecher sähen - womit zugleich ein Publikumssegment genannt wird, auf welches diese Radioteatros abzielen. Doch noch sollte es lange dauern, bis das Fernsehen nach Peru kam.

Radioteatros, - so berichtet uns der Erzähler - wurden im Übrigen in Serie hergestellt, und zwar trotz ihres kreolisch-peruanischen Beigeschmacks nicht etwa in Peru, sondern in Havanna, wo eine Art „imperio radiotelevisivo“10 herrschte. Kubas Hauptstadt war in jenen Jahren in der Tat eine Art Drehscheibe marktgerechter Produktionen für einen gesamtlateinamerikanischen Hörer- und Zuschauerkreis. Wir haben es also mit authentischer Massenproduktion zu tun, die rasch kommerzialisiert und umgesetzt wird, eine Produktion, in welcher auch das scheinbar ,Authentische‘ nichts anderes als pures Marktkalkül darstellt. ,Peruanisch“ ist folglich keine territoriale Produktion, sondern eine transnationale und in diesem Falle transareale Strategie großer Unterhaltungskonzerne, die von der Karibik aus auch für einen andinen Raum produzieren.

In den Augen des Chefs erscheint der junge Varguitas als eine Art Intellektueller seit ersterer eine von dessen Erzählungen in der Sonntagsbeilage seiner Tageszeitung gesehen hatte. Man sieht und erkennt deutlich: Schreiben ist nicht gleich Schreiben, Medium ist nicht gleich Medium. Und es bewahrheitet sich die alte Erkenntnis von Marshall McLuhan: „the medium is the message“, das Medium ist

9 Ebda., S. 13.

10 Ebda., S. 14. 
die eigentliche Botschaft. ${ }^{11}$ Denn eine Erzählung, die im Feuilleton einer Tageszeitung oder in Buchform erscheint, bleibt nicht dieselbe Erzählung, wenn sie über Radio läuft.

Übrigens werden die Radioteatros nicht nach Seiten, sondern nach Gewicht verkauft. Deutlicher hätte eine Stellungnahme zum Unterschied zwischen hoher Literatur einerseits und mediatisierten Schreibformen andererseits auf Ebene faktischer Bedingungen nicht ausfallen können. Unmittelbar vor der Ausstrahlung werden zahlreiche ,Kubanismen“ freilich immer noch rechtzeitig in ,Peruanismen“ umgebaut. Das nennt man intralinguale Übersetzung, eine Art „Rewording“ oder Transposition innerhalb derselben Sprache, aber für ein jeweils anderes Zielpublikum in Lateinamerika. Dass bisweilen - wie es im Roman heißt - ganze Kapitel auf dem Seeweg verloren gingen oder im Archiv ein Fraß der Ratten wurden, konnte dabei nicht weiter stören: Die paar fehlenden Gramm waren leicht zu schreiben.

Doch nun taucht eine neue Romanfigur auf. Der Ich-Erzähler fühlt sich als „hombre completo“ von achtzehn Jahren und kommt mittlerweile für einen Teil seiner Lebenshaltungskosten alleine auf. Er wird von der gerade frisch geschiedenen und aus Bolivien eingereisten Tante Julia, die sich schon wieder auf Bräutigams-Schau befindet, zunächst wie ein kleiner Junge behandelt und mit Wangenkuss artig begrüßt, womit zugleich eine gewisse innerfamiliäre und damit latent inzestuöse - Dimension in die sich nur sehr langsam anbahnende Liebesbeziehung eingeblendet wird. Mich interessiert dabei weniger die natürlich autobiographisch fundierte Liebesbeziehung als solche, in welcher im übrigen Tante Julia über die weitaus größere Erfahrung und Liebespraxis verfügt, sondern die Tatsache, dass sich diese Liebesbeziehung zunächst nicht in der gemeinsamen Lektüre eines Buches anbändelt wie noch bei Dante in der berühmten Episode von Paolo und Francesca. Nein, die Zeiten und die Medien haben gewechselt!

Vielmehr entflammt die Liebe beim gemeinsamen Kinobesuch, also beim gemeinsamen Konsum eines anderen Mediums, welches sich mit Hilfe bewegter Bilder ausdrückt. Auch in dieser Beziehung findet sich gleichsam eine mediale Konkurrenz- und Komplementärsituation, die nicht uninteressant ist, wenn wir etwa an Manuel Puigs Roman El beso de la mujer araña denken. Das Kino liefert genügend Stoff für eine beiderseitige „concupiscentia oculorum“: Die Liebe geht hier nicht durch den Magen, sondern durch die Augen. Man tut eben, was man sieht, und man sieht zu, dass man es schnell tut ...

11 So der vielzitierte Kernsatz des kanadischen Medienwissenschaftlers McLuhan, Marshall: Understanding Media: The Extensions of Man. New York: Mentor 1964. 
Jedenfalls geht diese umcodierte Paolo-und-Francesca-Episode auf die in allen Liebesdingen erfahrene Tante Julia zurück, die gleich beim ersten Treffen schon anregt, einmal gemeinsam ins Kino zu gehen. Mit Literatur und Intellektuellen hat sie nicht viel am Hut, wohl aber mit den bewegten und bewegenden Bildern, die zum Herzen sprechen. Und sie hat ein großes Herz. Ihre Lebens- und Liebesformen sind medial anders vorstrukturiert, und sie lassen den jungen Mann nicht kalt. Der erste Film, den sich Julia und Marito anschauen, stammt aus der damals sehr erfolgreichen mexikanischen Filmproduktion und heißt sinnigerweise Madre y amante, wodurch das seit dem Roman des 19. Jahrhunderts omnipräsente inzestuöse Element betont wird. Sie sehen schon, wie wunderbar komplex Mario Vargas Llosa seine Erinnerungen fiktional durchstrukturiert hat

Letztlich wird es dem männlichen Ich-Erzähler nichts helfen, gegenüber Tante Julia zu behaupten, dass es die Liebe eigentlich nicht gebe, da sie die Erfindung eines Italieners namens Petrarca und einiger Troubadoure sei. Da ist aus Sicht des Literarhistorikers einiges dran, wenn wir mit Denis de Rougemont die Geschichte der Liebe im Abendland durchforsten. ${ }^{12}$ In den Zeiten medialer Massendistribution sind derlei Vorstellungen allerdings von gestern. Das heißt, sie wirken fort, bedienen sich zum Teil aber anderer Medien. Maritos „erotischbiologische Theorie“ kann die schöne Tante Julia nicht überzeugen; und es wird nicht mehr lange dauern, bis aus Marito ein „marido“, Julias Ehemann, geworden ist.

Eine weitere Hauptfigur des Romans lässt nicht lange auf sich warten und kommt ebenfalls aus Bolivien an: eben der bereits erwähnte Pedro Camacho. Camacho wird im Handumdrehen angeheuert und arbeitet fortan exklusiv für Radio Central, eine feste Anstellungssituation, die bereits darauf verweist, dass wir es hier mit gänzlich anderen ökonomischen und arbeitstechnischen Strukturen zu tun haben als im Bereich der Literatur. Übrigens wird als konkurrierender Bereich auch die Universität nicht ausgespart, ist doch Maritos bester Freund ein junger Mann, der früher der Star des Literaturdepartments der Katholischen Universität zu Lima gewesen war. Aus ihm wurde aber kein brillanter Doktorand und auch kein brillanter Lehrstuhlinhaber, der noch Gedichte und Kritiken beisteuern könnte; nein, er wechselte plötzlich und unerklärlich das Fach, ließ die Literaturwissenschaften Literaturwissenschaften sein und schrieb sich für Wirtschaftswissenschaften ein. Er ist kein gutes Beispiel für Sie!

Dieser junge Mann hatte schlicht damit begonnen, die Literatur und alles, was mit ihr zusammenhing, zu hassen. Er hatte zuvor ganz peruanisch über Ricardo Palma promovieren wollen, arbeitete nun aber am Banco Central. Man sieht mit

12 Vgl. hierzu das Rougemont-Kapitel in Ette, Ottmar: LiebeLesen, S. 135-161. 
Verdruss: Die Attraktivität unserer Studiengänge ist nicht überall gewährleistet. Wie dem auch sei, Am Ende des ersten Kapitels taucht eben das kleine Männchen namens Pedro Camacho auf und bemächtigt sich der Schreibmaschine des Ich-Erzählers. Fortan lesen wir, ohne dass dies dem Lesepublikum angekündigt würde, jene Geschichten, die Camacho in unglaublicher Geschwindigkeit in die Maschine tippt und wenige Stunden später bereits aufführt. Schauen wir uns diese wundersame Figur einmal näher an:

\footnotetext{
Mit einer raschen, automatischen Bewegung streckte das Männchen augenblicklich eines seiner Ärmchen aus, machte einige Schritte in meine Richtung, bot mir eine Kinderhand an und stellte sich, begleitet von einem erneuten höfischen Knicks, mit seiner kostbaren Tenorstimme vor:

- Ihr Freund Pedro Camacho, Bolivianer und Künstler.

Er vollführte Geste, Bewegung und Formel noch einmal mit Pascual, der augenscheinlich einen Moment höchster Konfusion erlebte und zu entscheiden unfähig war, ob sich das Männchen über uns lustig machte oder sich immer so verhielt. Nachdem er uns zeremoniell die Hände gedrückt hatte, drehte sich Pedro Camacho zum Informationsdienst um [...]. Er nahm sich einige Sekunden Zeit, bevor er uns mit musikalischen Worten bedachte, begleitet von der Gestik eines sich verabschiedenden Zauberers:

- Ich verüble es Ihnen nicht, ich bin an das Unverständnis der Leute gewöhnt. Leben Sie wohl, meine Herren! ${ }^{13}$
}

Diese schöne Vorstellungsszene, nach welcher die Literatur des Pedro Camacho die Leserschaft ,überflutet', ist recht hübsch konstruiert und verdient es, ein wenig genauer betrachtet zu werden. Zur Erläuterung: Pedro Camacho ist gekommen, um sich sein Arbeitsgerät - eine Schreibmaschine der Marke Remington - unter den Nagel zu reißen, selbstverständlich mit Unterstützung der Geschäftsleitung, welche dieses Arbeitsgerät wesentlich effektiver in den Händen des bolivianischen Kunstschreibers eingesetzt sieht. Der Auftritt von Pedro Camacho erzeugt einen komischen Effekt, ist für den kleinen Bolivianer selbst aber in keiner Weise komisch. Ganz im Gegenteil, Er nimmt sich und seine Kunst überaus ernst. Mehr noch, er beklagt sich als Künstler über das Unverständnis der Welt gegenüber seinem Tun und der von ihm repräsentierten Kunst, der er als überzeugter „artista“ huldigt.

Zugleich ist er eine Art Zwitterwesen, insoweit man nicht weiß, ob er sich in der Realität oder der Fiktion bewegt. Nicht umsonst wirkt er wie ein Zauberer, und zwar als „prestidigitador“ wie einer, der mit den Fingern zaubert, was angesichts der Schreibmaschine ja keineswegs überraschend ist. So ist Pedro Camachos Stimmorgan auch eine überaus melodiöses, womit auch hier in der Realität

13 Vargas Llosa, Mario: La tía Julia y el escribidor, S. 26. 
schon das spezifische Medium seiner Hör-Kunst in akustischer Inszenierung vernehmbar wird. Vom reinen Augenschein her ist nicht zu entscheiden, ob sich der Bolivianer nun über seine Gesprächspartner lustig macht oder nicht: Er ist ein Wesen, das sonderbar zwischen den Stühlen, den Konventionen, zwischen Schein und Sein oszilliert.

Denn Pedro Camacho ist Künstler und kein Künstler, Zauberer und kein Zauberer, ist ironisch und ist es doch nicht, ist ein Arbeiter und kein Arbeiter. Er ist als reale literarische Figur selbst bereits so ambivalent wie jene Unzahl an Geschichten, deren Ende im Roman stets offenbleibt, weil man immer noch eine weitere Folge hören muss, um das vermeintliche ,Ende“ der Geschichte erfahren zu können. So ist Pedro Camacho die Verkörperung seiner literarisch-massenkulturellen Gattung, seines Lebens und Schreibens selbst. Die unendlichen Geschichten, die er unermüdlich in die Maschine hämmert, sind ebenso Kunst und Kunsthandwerk wie er selbst: Alles ist für ein möglichst breites Publikum gemacht.

Ich kann in der Folge leider die Vielzahl von Geschichten nicht darstellen, die im Roman ständig weiter proliferieren. Wie schon gesagt: Es besteht eine gewisse strukturelle Ähnlichkeit mit Italo Calvinos schönem Roman Wenn ein Reisender in einer Winternacht. Die zahlreichen einmontierten Geschichten sind durchaus einer Analyse wert und betreffen eine Vielzahl ästhetischer Fragestellungen, die für unsere aktuelle Vorlesung von Bedeutung sind. Im Grunde zeigen sie wie in einem Kaleidoskop unterschiedliche Facetten und Fragmente der peruanischen und lateinamerikanischen Gesellschaften auf, wobei - sehen wir von der großen Katastrophe am Ende einmal ab - alle Geschichten rund um das Thema „Sex and Crime“ radikal offen bleiben.

Zweifellos ließe sich sagen, dass diese auf den ersten Blick so trivialen Geschichten eine „opera aperta“ im Sinne Umberto Ecos bilden und Bestandteile eines Mobile sind, als dessen Einzelteile sie sich bewegen und in ständig neuen Konfigurationen erscheinen. Bemerkenswert und aufschlussreich ist besonders, dass jeweils bestimmte Unterhaltungsmedien von Bedeutung sind, so etwa schon in der ersten Geschichte das Medium Buch in Form der Bestseller, welche ein angesehener Arzt neben seiner Körperertüchtigung nie zu kaufen vergisst.

Bereits die erste eingeblendete Liebesgeschichte ist inzestuös, da sie sich zwischen zwei Geschwistern anbahnt. Dies ist seit dem 19. Jahrhundert nicht allein im französischen, sondern auch im lateinamerikanischen Roman Standard und ein Lieblingsthema des Feuilletonromans - glauben Sie bloß nicht, es sei neu! Es taucht hier freilich in einer burlesken und verzweifelten Variante zugleich auf. Denn es geht um die erzwungene Hochzeit der schönen Eleanita mit einem weniger hübschen Absolventen einer US-amerikanischen Universität, der fest an die Liebe glaubt. Doch die Heirat soll nur dazu dienen, Eleanitas 
Schwangerschaft durch ihren eigenen Bruder bestmöglich $\mathrm{zu}$ kaschieren. Wie am Ende aller Geschichten Pedro Camachos, die sämtlich „cursi“ sind, folgt eine Serie an Fragen, wie es wohl mit den Protagonisten und der Geschichte weitergehen werde. Dabei ist es durchaus möglich, einzelne Teile der Geschichte unter anderen Geschichten weiterzuverfolgen.

Die kleine, aber hyperaktive Gestalt Pedro Camachos ist für den jungen Marito, der selbst seinen Träumen, ein Schriftsteller zu sein, sehnsuchtsvoll nachhängt, eine ständige Faszination und Herausforderung. Denn Pedro Camachos Produktivität ist atemberaubend, da er schon in den frühen Morgenstunden zu schreiben beginnt, bis weit über die Mittagszeit hinaus weiterschreibt und - wenn er dann endlich geistig etwas müder geworden ist - schließlich nachmittags als Schauspieler seine eigenen Texte interpretiert. Wir spüren bei dieser Beschreibung etwas von der eisernen Disziplin, mit der Mario Vargas Llosa selbst zu schreiben pflegt und seinen Arbeitsalltag gestaltet.

Da bleibt zum Schlafen, geschweige denn für andere Aktivitäten, nur wenig Zeit: Gezielte Schlafreduktion ist das Motto. Auf die Frage, wie es ihm in Lima ergehe, antwortet Camacho, dass es ihm wie überall gut gehe, sei doch das Vaterland des Künstlers die Welt. Diese Figur besitzt viele Aspekte, in denen wir durchaus Positionen erkennen können, die sich mit jenen von Mario Vargas Llosa in Verbindung bringen ließen. Es ist also keineswegs so, dass Pedro Camacho als Kontrast- und Negativfolie für jene Positionen herhalten muss, die sich dann positiv in Varguitas kristallisieren. Vielmehr ist es gerade das Faszinosum des Schreibens, des Erfindens sowie sich selbst Erfindens durch das Schreiben, das in der Figur Pedro Camacho zum Ausdruck kommt. Dieses Schreib-Männchen hat es fürwahr in sich!

Selbst Tía Julia kann sich seiner Anziehungskraft nicht entziehen, trotz oder gerade wegen der Radikalität dieser Figur. Dagegen sind Maritos Schreibversuche intellektuelle Fingerübungen, die braven Etüden gleichen. Dazu zählen etwa die Versuche - und man sieht hier deutlich die Spuren, welche dieser argentinische Schriftsteller in der Postmoderne hinterlassen hat -, einen „cuento“ im Stil von Jorge Luis Borges zu schreiben, eines Autors, den Marito gerade erst kennengelernt hatte. Doch in dieser fleißigen Schreibübung misslingt zumindest das zunächst, was deren etwas pompöser Titel verspricht: nämlich den qualitativen Sprung zu machen, „El salto cualitativo“. Im Gegensatz zu Pedro Camacho schreibt Marito mittags sowie nachts; und schon nach der Niederschrift des ersten Satzes findet der angehende Schriftsteller diesen bereits furchtbar. Aller Anfang ist schwer! Ganz im Flaubert'schen Sinne braucht es viel Zeit, bis sich die ewige Orgie, die „orgía perpetua“, endlich einstellen will.

Pedro Camacho gelingt es, anhand eines simplen Plans der Stadt Lima - und ohne die peruanische Hauptstadt wirklich zu kennen, schreibt er doch die ganze 
Zeit - die wesentlichen Hauptspielorte festzulegen und eine Art künstlerischer Kartographie zu entwerfen, die dem französischen Soziologen Pierre Bourdieu Freude bereitet hätte. Es lässt sich wirklich nicht behaupten, dass Pedro Camachos Kunst schlicht mimetisch wäre. Sie ist vielmehr arrogant, indem sie sich das Recht nimmt, die Dinge neu zu benennen, sie an sich zu reißen und mit ihrem eigenen Bedeutungssystem aufzuladen, das freilich immer an Extremen, an arm und reich, Tag und Nacht, schön und hässlich - und was es an Gegensätzen noch mehr gibt - orientiert ist. Pedro Camacho bleibt gleichsam ein Strukturalist in Aktion, der seinen Diskurs unverdrossen um Oppositionspaare aufbaut.

So interessieren ihn Madonnen oder Prostituierte, nicht aber die „mesocracia“, die mittleren Figuren, für die sich auch sein Publikum nicht interessieren könne. Alles, so Pedro Camacho, komme aus ihm selbst, ganz Argentinien etwa sei mit seinem Denken angefüllt, und viele hätten ihn dort kopiert, er selbst aber habe noch von niemandem abgeschrieben. Auch auf Ebene einer bewussten und expliziten Intertextualität unterscheidet sich Pedro also grundlegend von Marito, dem Schriftstellerlehrling. Pedro Camachos Bibel ist allerdings ein Buch, das Zitate der einhundert besten Schriftsteller der Welt enthält. Auf diese Wunderwaffe, die keine Kanone, wohl aber den Kanon anbietet, greift er zurück, eignet sich diese Zitate an, ohne auf ihren jeweiligen Kontext zu achten oder gar zu antworten. Es geht ihm lediglich um altbewährte Lösungen für seine beliebig zahlreichen Geschichten.

Mario alias Marito ist von dieser Art des Schreibens fasziniert und vergisst darüber sogar sein ,Date‘ mit Tante Julia im Kino, was letztere gar nicht goutiert, sondern wütend macht. Auch auf dieser Ebene ist eine Rivalität der Medien Grundlage für die spezifischen Formen des Schreibens und der Handlungsmuster des Romans. Übrigens ließe sich diese Dimension des Mediums als Konkurrenz noch weiter verfolgen in der Figur jenes „escribano“, der spiritistische Sitzungen abhält, als Medium gilt und ständig irgendwelche Geschichten über das Jenseits erflunkert. Auch dies ist eine Art konkurrierender Textproduktion, welche in La tía Julia y el escribidor erscheint. Gut möglich ohnehin, dass Vargas Llosa sich an Roland Barthes' Überlegungen zu verschiedenen Formen des Schreibenden und Schriftsteller-Seins orientierte, in denen der französische Literaturtheoretiker etwa vom „écrivain“ und vom „écrivant“, aber auch vom „scripteur“ schrieb. Denn Schreiben ist nicht gleich Schreiben. Und es besteht kein Zweifel, dass sich Pedro Camacho nicht allein am Ideal des „scriptible“, sondern auch am „lisible“, folglich nicht nur am leicht Schreibbaren, sondern auch am leicht Lesbaren orientiert.

Eine gewisse Monotonie dieser liebesgetränkten, aber nicht liebestrunkenen Geschichten lässt sich freilich nicht verbergen: Denn alle Verstorbenen sitzen im Fegefeuer und lassen Grüße ausrichten. Tante Julia kennt übrigens außer dem 
Kino noch andere Register der Massenkultur: So beginnt sie den jungen Mann, der langsam bemerkt, dass es sich bei seiner Tante um eine sehr schöne Frau handelt, „Popeye“ zu nennen. Bald schon kommt es bei einem Tänzchen zum ersten zaghaften Kuss. Im Übrigen tauchen auch in den seriellen Geschichten Camachos, die stets auf die „flor de la edad“, die Jahre um die fünfzig und damit Camachos eigenes Alter, aufmerksam machen, weitere Medien der Massenkultur auf. Unvermeidbar ist dabei im Bereich Comic auch der „Pato Donald“, der bereits im vierten Kapitel auftaucht: Entenhausen lässt herzlich grüßen! Ein weiterer Vertreter der Massenkultur begegnet uns dann im fünften Kapitel, ein Schlagersänger, der bei Radio Panamericana vorbeikommt und von seinen fanatischen Verehrerinnen, die ihm stets an die Wäsche gehen, nichts Gutes erwarten darf. So kann das Bad in der Menge, die Begeisterung der Massen, auch für deren Objekte und Symbole Risiken bergen. Zu diesem Zeitpunkt konnte Vargas Llosa wohl noch nicht ahnen, dass er einige Jahre später selbst zum Superstar werden würde. Ich erinnere mich sehr gut daran, wie er bei einer Veranstaltung des Instituto Cervantes in Frankfurt am Main durch ein Spalier von kreischenden Verehrerinnen gehen musste und ihn seine Patricia auf dem Weg zur Podiumsdiskussion - ich ging direkt hinter dem Paar - besonders fürsorglich und streng an die Hand nahm.

Tante Julia und Marito sind sich mittlerweile nähergekommen, auch wenn sich die Tante standhaft weigert, sich dem Vorwurf von Seiten der Familie auszusetzen, eine „corruptora de minores“ zu sein, eine Verführerin Minderjähriger. Aber alles geht seinen vorbestimmten Weg. Varguitas jedenfalls erzählt ihr Geschichten: diesmal nicht die aus seiner eigenen Vergangenheit, sondern aus seiner Zukunft. Es sind Bilder eines Lebensprojekts, eines Klischees vielleicht, nämlich als Schriftsteller in Paris, der „ville lumière“, zu leben - Klischee und ein Lebenstraum, den sich Mario Vargas Llosa zu diesem Zeitpunkt längst erfüllt hatte. Ebenso Marito Varguitas wie Mario Vargas Llosa sollten dieses Lebensprojekt folglich mit gelebtem Leben füllen.

Damit wird zugleich deutlich: Die Massenkommunikation und ihre Klischees schreiben stets die Texte und die Lebenserfahrungen mit, es gibt kein Entrinnen aus ihren Vorstellungen. Wir alle stehen unter dem Einfluss bunter Träume und Lebensentwürfe, welche über die Massenmedien portiert und transportiert werden. Nicht umsonst erzählt Marito seiner Tante, dass er Schriftsteller habe werden wollen, seit er zum ersten Mal Alexandre Dumas gelesen habe. Sollte dieses friktionale Element authentisch sein, so sei Alexandre Dumas, der über ganze Schreibateliers befehligte, gebührlich belobigt: Er trug dazu bei, einen Literaturnobelpreisträger zum Schreiben zu bewegen.

In Gestalt des französischen Autors haben wir den frühen Vorläufer industrieller Romanproduktion und letztlich auch Pedro Camachos Ahnherrn vor uns, der freilich weit jenseits der Feuilletons ein effektiveres und ein noch breiteres 
Massenpublikum erreichendes Medium bedient. Nach all dem diagnostiziert die zweiunddreißigjährige geliebte Tante kühl, dass ihr noch achtzehnjähriger Lover wohl an Hunger sterben wolle: Schriftsteller zu werden sei kein Beruf, von dem man wirklich leben könne. Das Lebensprojekt eines Schriftstellers ist eben nicht für alle attraktiv. Tía Julia ist eben „terriblemente aliteraria“: Mit Literatur hat sie nichts im Sinn und weiß zugleich um die Inzesthaftigkeit der aufkeimenden Beziehung, in der sie fast die Mutter des Heranwachsenden sein könnte. Und Mütter sind mit den Träumen und Lebensprojekten ihrer hoffnungsvollen Sprösslinge nicht immer einverstanden.

Doch noch sind Tía Julia und der „escribidor“ kein wirkliches Paar, noch kommt es nicht zum körperlichen Vollzug der Liebe. Der abgedunkelte Kinoraum ist Bühne für ausgetauschte Küsse und Zärtlichkeiten, die irgendwie amorph und medial vermittelt bleiben. Es bleibt einstweilen bei dem, was man im Deutschen „Schmusen“ nennt, vielleicht ein heute etwas aus der Mode gekommenes Tätigkeitswort. Auch diese Verhaltensmaßregeln sind gesellschaftlich und kulturell bestimmt und entsprechen der Vorstellungswelt von Miraflores, dem gut situierten Viertel, in welchem die Familie lebt. Auch hier scheint es aus den vorgestanzten, vorfabrizierten Lebensprojekten kein Entrinnen zu geben.

Im Übrigen zählt Tante Julia mittlerweile auch zu den Hörerinnen von Pedro Camachos Radioteatros, denen sie bisweilen tränenreich folgt. Sie ist im Grunde eine ideale Hörerin und ganz mit ihrem Herzen dabei. Eine Vielzahl unterschiedlicher Rezeptionssituationen erscheint in der Folge im Roman, wobei es eben die Radioteatros sind, und nicht etwa (belletristische) Literatur, die es laut Großeltern erlauben, unmögliche Dinge im realen Leben zu erleben. Ja, da haben die Großeltern Recht, denn wir erleben Fiktionen nicht grundsätzlich anders, als wir dies mit Teilen dessen tun, was wir für Realität halten. Unsere Realität ist im Übrigen aus vielen Fiktionen gemacht, gleichviel, ob wir Börsennachrichten hören oder mit einem Freund über dessen Aufstiegspläne sprechen. Literatur bietet uns nicht nur ein breites Lebenswissen an, sondern ein Erlebenswissen, mit dessen Hilfe wir Dinge erleben können, die wir in unserem Leben sonst niemals erlebt hätten.

Kein Wunder also, wenn die Zuhörerzahlen von Radio Central bald unaufhörlich in die Höhe schnellen und nun auch die Zeitungen über den Künstler Pedro Camacho berichten: Massenkommunikation zieht Massenkommunikation nach sich. Auch aus unseren Talkshows wissen wir, dass Journalisten am liebsten Journalisten einladen, da in diesem Fall die Verständigung viel einfacher funktioniert. Doch Pedro Camacho gehört nicht $\mathrm{zu}$ dieser Sorte: Er schottet sich ab und will keine Fans und Journalisten empfangen, seine Zeit als Künstler ist ihm dafür zu kostbar. Wir hatten ja bereits gesehen, wie sehr der kleine Bolivianer sich selbst als Künstler einschätzt und schätzt. 
Seiner Kunst ordnet er in der Tat alles unter. Es ist eine Kunst nicht nur der Schreibmaschine, der Abfassung von Texten in Gewichtsportionen, sondern auch der Stimme, der klangvollen Stimmen. Dabei hat Camacho bei der Gestaltung dieser Stimme eine Reihe von Tricks auf Lager: So empfiehlt er seinen Sprechern, vor Liebesszenen zu masturbieren, um so die Stimme zu schwächen und ihr eine besondere Qualität zu verleihen. Auch dies ist eine Art ,Körpersprache“ in der Stimme, der Stimmkultur, und es wäre interessant, diese Dimension im Roman weiter zu verfolgen. Pedro Camachos derart körperliche, radioteatrale‘ Arbeit am Körper-Haben, am Objekt Körper, die etwas Absolutes und Fanatisches hat, fasziniert nicht nur den Erzähler, sondern auch die Mitwirkenden und hinterlässt Spuren beim Publikum. In den Augen der Schauspieler des Radios, der Sprecherinnen und Sprecher der Radioteatros, erscheint Pedro Camacho als Hohepriester der Kunst.

Ich möchte Ihnen zumindest einen kleinen Auszug aus dem Kunstschaffen Pedro Camachos nicht vorenthalten. Wir sind mitten in einer Geschichte, befinden uns im sechsten Kapitel und es geht um die Aufklärung eines Vergewaltigungsvorwurfs, wobei die einzelnen Zeugen befragt werden. Bald wird deutlich, dass das Mädchen, das von seinen Eltern oder Großeltern als Opfer benannt wird, in Wirklichkeit eine Lolita ist, die unter die Haube gebracht werden soll: Mit Hilfe des Vorwurfs einer Vergewaltigung sucht man, den Nachbarn zur Heirat zu zwingen. Die Inszenierung ist nicht von schlechten Eltern, insbesondere dann, wenn das Mädchen vorführen soll, was ihr widerfahren ist. Auch hier lässt die Massenkultur mit ihren Sexualklischees grüßen:

Aber als Sarita Huanca Salaverría die Andeutung des Richters hörte, entflammte sie wie ein Kampfhahn, der Blut roch, drehte voll auf und steckte alles in einen aufreizenden Monolog und eine mimisch nachahmende Darstellung, welche den Atem von Dr. Don Barreda y Zaldivar stocken ließ und Dr. Zelaya in eine offen gesagt ungehörige körperliche Unruhe stürzte (vielleicht masturbierte er gar?). Der Mechaniker hatte die Türe sooo berührt, und als sie sie öffnete, hatte er sie sooo angeschaut, und dann hatte er sooo gesprochen, und danach hatte er sich sooo hingekniet, wobei er sich sooo an sein Herz gefasst hatte, und er hatte sich ihr sooo erklärt, wobei er ihr schwor, dass er sie sooo liebe. Betäubt und hypnotisiert sahen Richter und Sekretär diese Kinds-Frau an, die wie ein Vogel mit den Flügeln schlug, sahen, wie sie wie eine Tänzerin steil nach oben ging, sahen, wie sie sich bog und hob, wie sie lächelte und sich erregte, wie sie ihre Stimme veränderte und verdoppelte, wie sie sich selbst und dann Gumercindo Tello nachahmte, und wie sie schließlich in den Fenchel fiel und (sich, ihm) ihre Liebe erklärte [...]; und das geschwätzige Opfer erklärte weiter, dass der Mechaniker sie mit einem Messer sooo bedrohte, und sich sooo auf sie gestürzt habe, so dass sie sooo umfiel, und er sich sooo auf sie legte, und dass er sooo an ihren Rock gefasst habe, und in diesem Augenblick richtete sich [...] der Richter in seinem Sessel auf und brüllte: „Genug!“14

14 Vargas Llosa, Mario: La tía Julia y el escribidor, S. 140. 
Alle Bereiche des Lebens erscheinen aus der Perspektive unterschiedlicher Medien als Inszenierungen. Sie verweisen weniger auf eine ,harte‘ Realität als auf deren Anverwandlung mit Mitteln der Massenkultur. Das Leben erscheint dann nicht nur als Film, es ist ein Film, eine Radionovela, eine mehr oder minder geschickte Inszenierung, die wir alle schon kennen. Diese sollten wir nicht mit Realität und Mimesis verwechseln, sondern mit der Fähigkeit der Massenkultur in Verbindung bringen, alles zu resemantisieren, so dass es aus diesen künstlerisch deformierten und angeeigneten Klischees keine Ausgänge, keine Fluchtmöglichkeiten mehr zu geben scheint.

Es sei denn, wir würden sie unsererseits wiederum mit Hilfe des Mediums Kunst bannen. Denn die Kunst könnte die falschen Wände medialer Begrenzung, könnte die Klischees und Stereotypen, die vorgefertigten Vorstellungen und Lebensmuster durchstoßen und verändern. Genau an dieser Stelle, so scheint mir, kommen wir zum entscheidenden Punkt des Romans. Denn er widmet sich gerade dieser Fragestellung zwar mit Ironie, aber durchaus absichtsvoll und nicht ohne Hoffnung.

Denn die Kunst hat noch nicht aufgegeben, auch wenn sie selbst im Bild eigener künftiger Schriftstellerexistenz vergangenen Bildern und Orten nachhängt und nachfolgt. Dies gilt auch für die eben gelesene Passage aus einer der Geschichten Pedro Camachos. Die kleine Sara ist eine Lolita, die doppelt und dreifach gelesen wird: die als kleines verführerisches Mädchen, als Kinds-Frau, als peruanische Anverwandlung von Vladimir Nabokovs Lolita und als literarische Darstellung all dieser Ebenen auf einer höheren Ebene gelesen werden kann. Zugleich macht diese Passage auf eine Beschränkung des Mediums Radioteatro aufmerksam, denn das ständig wiederholte „asi““ oder „sooo“ weist letztlich auf das Fehlen des Bildes im Radio hin, welches der Zuhörer und die Zuhörerin selbst ergänzen muss. Und zwar genau wie das Lesepublikum, nämlich mit Mitteln der Hypotypose, dem Erzeugen von Bildern im Kopf, die bei jedem von uns anders ausfallen. Wir alle haben eine andere Sarita vor dem inneren Auge, die einen jeweils anderen Rock trägt und sich anderer Gesten bedient, je nachdem, ob wir schon einmal in unserem Leben in Peru gewesen sind und vergleichbare Mädchen kennen gelernt haben.

Ich kann an dieser Stelle nicht auf die verschiedenen eingeschalteten Histörchen eingehen und möchte mich auch nicht um die an Peripetien reiche Geschichte der Liebe zwischen Marito und Julia kümmern. Entscheidend für unsere Fragestellung scheint mir aber zu sein, dass Vargas Llosas Roman in Form mehrfacher Selbstbezüglichkeit, seiner Konstrukthaftigkeit und nicht zuletzt seiner Metadiskursivität eine Art postmoderne Anverwandlung einer medialen Problematik leistet, welche zur nun notwendig gewordenen Beziehung zwischen Literatur und Massenkultur essentiell hinzutritt. Dies mag mit Vargas Llosas 
Erfahrungen selbst zusammenhängen, der ja schon seit Ende der siebziger Jahre zu einem internationalen Star, einer „superestrella“ geworden war. ${ }^{15}$ Er sollte bald schon sein eigenes Fernsehprogramm bekommen und musste letztlich sein eigenes Schreiben tagtäglich mit den verschiedensten Massenkommunikationsmedien in Einklang oder zumindest doch in Beziehung bringen, also stets darum bemüht sein, den Anforderungen von Fernsehen, Film und Radio, Boulevardzeitschriften und Intellektuellenpresse sowie vielen anderen medialen Erzeugnissen mehr zu entsprechen. Der peruanische Autor wusste, wovon er sprach, wenn er seinem Bolivianer Pedro Camacho keine Minute Ruhe gönnte und ihn pausenlos schreiben ließ.

Nicht umsonst ist Mario Vargas Llosa als einer seiner maßgeblichen Schriftsteller mit dem Boom identifiziert worden, mithin als Vertreter jener Periode lateinamerikanischer Literaturentwicklung, in welcher sich die Vermarktung literarischer Werte und Bilder in einem zuvor nie gekannten Ausmaße realisiert und vollzogen hat. Spätestens seit dem Boom der lateinamerikanischen Literaturen mussten sich die zumeist männlichen Schriftsteller gegenüber den sie umgebenden und durchdringenden Medien der Massenkommunikation positionieren und zugleich in Szene setzen. Dies war für die Generation Gabriel García Márquez, Mario Vargas Llosa, Carlos Fuentes oder José Donoso Segen und Fluch zugleich.

Das dieser Sachverhalt keineswegs nur die Dimension der Visualisierung und damit Kino, Film oder Fernsehen betraf, liegt auf der Hand. Diesen Fragestellungen, aber auch künstlerischen Herausforderungen geht der peruanische Starschriftsteller in La tía Julia y el escribidor geradezu detektivisch nach. Die Nachfrage des Publikums reguliert den Markt: Dies bemerkt auch der „Balzac criollo“, der mit vier zeitgleichen Radioteatros begann, längst zehn simultan ablaufende Stücke permanent fortspinnt. Das macht täglich nicht weniger als dreiundzwanzig Minuten plus sieben Minuten Werbung, wobei letztere eben auch zunehmend ins Bewusstsein der Literatur und ihrer sozialen Reflexion tritt. Wenn wir das mit zehn multiplizieren, wissen wir, dass Pedro Camacho nicht weniger als fünf Stunden seiner kreativen Zeit im Studio verbringen muss: Die Niederschrift der einzelnen Kapitel darf fortan nicht mehr als das Doppelte an Zeit in Anspruch nehmen. Doch auch dies bedeutet zusätzlich etwa zehn Stunden täglich an seiner schönen Remington-Schreibmaschine.

Pedro Camacho ist folglich ein literarischer Schwerstarbeiter - und Zwangsarbeiter. Selbst ein Balzac hätte Schwierigkeiten gehabt, mit diesem Tempo

15 Vgl. hierzu Franco, Jean: Narrador, autor, superestrella. La narrativa latinoamericana en la época de la cultura de masas. In: Revista iberoamericana (Pittsburg) 114-115 (enero - junio 1981), S. 129-148. 
mitzuhalten. Das Motto „Nulla dies sine linea“ erscheint gegenüber derartigen Arbeitsbedingungen als nostalgische Reminiszenz an längst verflossene Tage. Da bleibt keine Zeit, um Bücher oder Zeitschriften und Zeitungen zu lesen. Die Texte müssen in der Tat, wie es im Roman so schön heißt, wie Würstchen produziert werden. Pedro Camacho ist Sklave seines großen Erfolgs.

Aber wie geht die ganze Geschichte aus? Welches Ende steht dem Zusammenspiel der Medien, welches Ende der Liebesbeziehung zwischen Tante Julia und dem jungen Marito bevor? Lassen Sie uns ans Ende von La tía Julia y el escribidor springen und sehen, wie sich die Dinge weiterentwickelt haben und bleiben wir uns dabei aber einer Tatsache bewusst: Die einzelnen eingebauten Geschichten sind keineswegs nur billiges Beiwerk, sondern Ansatzpunkte für metadiskursive Behandlungen! Auch in diesem Zusammenhang können wir eine Verschränkung von literarischem und theoretischem Diskurs beobachten, welche seit den sechziger Jahren und dem Nouveau Roman zunehmend die Schreibstrategien beherrscht - ohne freilich in Frage stellen $\mathrm{zu}$ wollen, dass Theorie schon immer eine Dimension von Literatur war. Wir können dies ebenso anhand der Geburtsurkunde des Romans, Miguel de Cervantes' Don Quijote de la Mancha, wie in dessen narrativen ,Schwangerschaftstests“, der Novela picaresca mit ihren „pícaros“ und „pícaras“ sehr deutlich beobachten. Aber in den Literaturen im Zeichen der Postmoderne spitzt sich dieses Verhältnis wesentlich zu.

Denn die spezifischen Formen des Aufeinander-bezogen-Seins von Textualität und Metatextualität sind seit den 60er Jahren verändert; und Vargas Llosa hat mit seinem so beeindruckenden Gespür für unterschiedlichste Entwicklungen all die kleinen „Tropismen“ künstlerischer Gestaltungsformen sehr frühzeitig erkannt. Nicht umsonst ist er ein Meister im Aufdecken jeweils sehr aufregender Fragestellungen und vielleicht mehr noch im Erkennen der jeweils gerade angesagten literarischen Gattungen, denen er - wie etwa dem lateinamerikanischen Diktatorenroman mit La fiesta del chivo - eine eigene Richtung gibt. In dieser Fähigkeit, diesem Sensorium für früh zu erkennende Literaturentwicklungen übertrifft ihn wohl im 20. und 21. Jahrhundert kein anderer lateinamerikanischer Schriftsteller.

Wie enden nun aber die ganzen Geschichten Pedro Camachos? Wir haben schon darauf hingewiesen, dass der Bolivianer zunehmend seine Geschichten durcheinanderbringt, worin man zunächst den Einfluss surrealistischer Schreibweise $\mathrm{zu}$ erkennen versuchte. Doch Pedro Camacho hat mit dem Surrealismus und den historischen Avantgarden nichts mehr gemein. Behelfsweise verwies man auch darauf, dass schon Honoré de Balzac in seinen Romanen der Comédie humaine immer wieder längst verstorbene Romanfiguren auferstehen ließ und auf diese Weise interessante Effekte entstanden. Doch die Dinge liegen auf dem Gebiet der bolivianisch-peruanischen Radioteatros anders: Pedro Camacho bekommt in 
der Tat die Figuren all seiner gleichzeitig verfassten Fortsetzungskapitel nicht mehr auf die Reihe und versinkt förmlich in den Fluten all jener Gestalten, die er sich ausgedacht hat.

Daher greift er zu einem Mittel, das offensichtlich bereits ein englischer Autor der Gothic Novel verwendete: Er lässt seine ganzen Protagonisten einfach in einer riesigen Hekatombe verschwinden. Alle (oder zumindest fast alle) kommen in einem Fußballstadium bei einer Massenhysterie um, so dass sich ihre Schicksale wie ihre Leiber vermengen und zu einer einzigen „sopa humana“ werden, wie es im Romantext vielsagend heißt. Wir können uns an dieser Stelle sicherlich die Details ersparen, auch wenn sie keineswegs uninteressant sind. Natürlich kommen zudem unsere Liebenden auf ihren bald erklommenen physischen Höhepunkt; aber auch diese Szenen, welche zum Teil sehr zärtlich geschildert werden, können wir uns hier buchstäblich schenken. Mario Vargas Llosa gab hier sein erstes Eheleben mit einer liebreizenden Tante zum Besten.

Pedro Camacho bekommt jedenfalls massive zerebrale Probleme. Er erleidet einen mentalen Kollaps, der im Zusammenbruch all seiner Radioteatro-Figuren literarisch transfiguriert wird. Wir erleben den Übergang in eine Zeit, in der Pedro Camacho einfachste Hilfsarbeiten in einer billigen Vorstadtzeitschrift ausführen muss. So endet seine Geschichte einigermaßen tragisch, während die von Marito alias Varguitas ihren unwiderstehlichen und unaufhaltsamen Aufstieg nimmt. Den „Radioteatros“ und ihren Zuhörerinnen und Zuhörern tut dies keinen wirklichen Abbruch: Denn an die Stelle des ausgefallenen Bolivianers werden in Radio Central jetzt wieder die kubanischen Massenproduktionen eingeführt. Alles geht so weiter wie gehabt, auch wenn der von Pedro Camacho ausgelöste Boom der Hörerzahlen nicht mehr wiederholt werden kann.

Das letzte Kapitel von La tía Julia y el escribidor enthält erneut eine Vielzahl autobiographischer Anspielungen, nicht zuletzt auf Vargas Llosas Beschäftigung mit einer gänzlich langweiligen wissenschaftlichen Materie. Denn Mario Vargas Llosa legte auf dem Gebiet der - wie wir in Deutschland sagen würden - Romanistik eine schöne Doktorarbeit über seinen damaligen schriftstellerischen Kollegen und zeitweiligen Weggefährten Gabriel García Márquez vor. Neben seiner in Madrid eingereichten Promotion verfasste er darüber hinaus eine Untersuchung, die später unter dem Titel La orgía perpetua von seiner großen Bewunderung, ja Liebe zu Flaubert Zeugnis ablegte. Vargas Llosa hat stets diese wissenschaftliche Arbeit - natürlich in einem zugänglichen Stil verfasst - neben seinen romanesken Arbeiten gepflegt. Vielleicht hat ihm dies als Poeta doctus immer wieder ein sicheres Näschen für die grundlegenden Veränderungen der Literaturszene seiner Zeit garantiert.

Nach acht Jahren Ehe trennte sich Vargas Llosa aber nicht nur von der romanistischen Beschäftigung mit einem alten literarischen Weggefährten, sondern 
auch von der flotten Tante Julia, um ein Jahr später eine nicht weniger flotte Kusine zu heiraten, wobei sich diesmal der innerfamiliäre Skandal in Grenzen hielt. Längst lebt der Ich-Erzähler in Europa, hält aber durch jährliche Reisen nach Peru den Kontakt zu seiner Heimat aufrecht. Nicht zuletzt bestehe das Problem seines Schreibens darin, dass alles einen Bezug zu Peru hatte, dass alle von ihm entworfenen Romandiegesen peruanisch situiert waren. Man kann anhand dieser Bemerkung schon absehen, dass sich Vargas Llosa nach neuen literarischen Landschaften umschaute. Und er sollte, wie bereits bemerkt, die Veränderungen seiner Romandiegesen mit unglaublicher Konsequenz vorantreiben.

Das zweite Problem seines Schreibens erblickt der Erzähler darin, dass er unter dem leide, was er ironisch seine „manía realista“ nannte. Schon erscheint der „Alto Marañón“ und damit das obere Amazonasgebiet als Schauplatz eines nächsten Romans, vorbereitet durch mehrere dokumentarische Reisen, die auch den realen Autor Vargas Llosa, darin ganz seinem Vorbild Gustave Flaubert treu, stets zu den Orten seiner Romane führten. Die schriftstellerische Akribie bei der präzisen Dokumentation seiner Romanschauplätze ist bei diesem Autor wahrlich beeindruckend!

Während einer seiner Reisen kehrt der Erzähler eines Tages nach Lima zurück und beobachtet, wie die Stadt zunehmend von Händlern und kleinen Verkäufern aus der „Sierra“, den Anden, in Besitz genommen wird. Im Zuge dieser soziologisch bedeutsamen Entwicklung ist auf den Straßen von Lima wieder vermehrt das Quechua zu hören. Die zeitliche Distanz, die das zwanzigste Kapitel auszeichnet, entspricht ganz jener Technik des „blanc“, die Vargas Llosa so sehr bei Flaubert - wie schon vor ihm Marcel Proust - bewundert hatte. Die Begegnung aus räumlicher und zeitlicher Distanz führt auch zu einem letzten Wiedersehen mit Pedro Camacho, welches ich bereits erwähnt habe. Wir erfahren, dass der kleine Bolivianer Camacho nun mit einer alten Frau zusammenlebt, die er schon früher hatte, die aber nie in Erscheinung getreten war und die Prostitution mehr schlecht als recht betreibt. In diesem unterhaltsamen und bisweilen lustigen, zugleich aber auch sehr ernsten Roman tragen alle Protagonisten - und ich schließe dabei keinen aus - ihre Haut zu Markte.

Die Tatsache der Prostitution, so scheint mir, wird metonymisch übertragen auf Camachos Kunst - aber eben nicht nur auf sie. Pedro Camacho jedenfalls nennt sie bewusst und bewundernd eine „artista“, und sie war es auch gewesen, die ihn aus dem Irrenhaus geholt hatte, in welchem er zeitweise gelandet war. Eine rein schematische Zuweisung positiver und negativer Elemente scheint mir hier nicht möglich: Die Figur des bolivianischen Schreibers und Schriftstellers bleibt bewusst in der Ambivalenz. Das Faszinosum Pedro Camacho ist für Marito freilich verbraucht und buchstäblich verglüht.

Doch die Wiedersehensfreude aller Beteiligten ist groß: Es wird ausführlich gefeiert. Und so kommt es, dass unser noch junger peruanischer Romancier 
von seiner dokumentarischen Erkundungsreise durch Lima etwas spät und sehr angeheitert nach Hause kommt. Dort erwartet ihn nicht mehr Tante Julia, sondern seine Kusine Patricia, die durchaus ihre gefährlichen Seiten hat. Dies besitzt vor dem Hintergrund seiner späteren dritten Ehe - von der Mario Vargas Llosa natürlich noch nichts ahnen konnte - einen deutlich prospektiven Zug. Schauen wir uns also - die Erkundung dieses Romans abschließend - den Beginn des letzten Abschnitts von La tía Julia y el escribidor an:

Als ich zum Haus von Tante Olga und Onkel Lucho kam (die als Schwägerin und Schwager zu meinen Schwiegereltern geworden waren), tat mir der Kopf weh, ich fühlte mich abgespannt und es wurde schon Nacht. Meine Kusine Patricia nahm mich mit einem wenig an Freundschaften interessierten Gesichtsausdruck in Empfang. Sie eröffnete mir, dass es schon möglich sei, dass ich mit meinem Geschichtchen, mich für meine Romane zu dokumentieren, Tante Julia den Mund hätte verschließen und den Barrabas spielen können, da die es nicht gewagt habe, mir etwas zu sagen aus Furcht davor, man könnte denken, sie wolle das Verbrechen einer Kulturbeleidigung begehen [...]; sie aber würde mich zerkratzen oder die Teller auf meinem Kopf zerschlagen. Tante Patricia ist ein Mädchen mit viel Charakter und sehr wohl in der Lage, das zu tun, was sie mir versprach. ${ }^{16}$

Wir bemerken mit einer gewissen Verwunderung: Auch das Finale dieses Romans ist nicht mehr und nicht weniger als ein Klischee, das Stereotyp vom zu spät nach Hause kommenden Gatten, der von seiner Frau zur Rede gestellt und beschimpft, ja bedroht wird. Alles ist wie in einem Radioteatro oder wie in der Realität. Zugleich bleibt alles in der Familie, denn von der Tante zur Kusine ist es kein weiter Weg; auch die verschiedenen Verwandten im Umfeld verändern nur ihre Bezeichnungen, bleiben aber die alten. Doch sollten wir besser nicht glauben, dass dies allein eine autobiographische Skizze aus dem Familienleben zu Hause bei Vargas Llosa sei. Die Klischees der Massenkultur bilden eben auch einen wesentlichen Aspekt dieses Romanschlusses, der letztlich eine Geschichte erzählt, die ebenso eine Radionovela hätte werden können. Und dann hat sie ihm sooo das Gesicht zerkratzt und danach gleich drei Teller sooo auf seinem Kopf zertrümmert, bis er bewusstlos sooo zu Boden sank. Die Konsequenz von alledem kennen Sie schon: Das Leben ist eine Radionovela - und die besten davon verkauft Mario Vargas Llosa.

Lassen Sie mich abschließend ein weiteres Moment anfügen! Es ist aufschlussreich, dass Vargas Llosa, der bis in die späten sechziger Jahre als klarer Vertreter der Linken und des Sozialismus agierte und sich spätestens seit den achtziger Jahren politisch rechtskonservativen und neoliberalen Positionen 
zuwandte, in der bisherigen Rezeption nur selten in postmoderner Beliebigkeit, pardon: als Autor im Zeichen der Postmoderne gelesen wurde. Diese Tatsache hat zweifellos mit dieser expliziten Politisierung zu tun, welche ein Ergebnis von Vargas Llosas eigener politischer Praxis ist, seinem Verständnis der Beziehung zwischen Literatur und Gesellschaft und damit letztlich seiner Überzeugung hinsichtlich der gesellschaftlichen Rolle des Intellektuellen und Schriftstellers, oder besser: des Intellektuellen als Schriftsteller. Er ist damit ein ganz typischer Vertreter des lateinamerikanischen Boom.

Lange Zeit wurden die Repräsentanten des Boom als gesellschaftskritische Autoren verstanden, die vom Glauben beseelt schienen, mit ihren literarischen Werken die Gesellschaften - zumindest in Lateinamerika - verändern zu können. Angesichts ihrer politisch-ideologischen Kritik stellten die Vertreter des Boom kein Phänomen dar, welches unter die Literaturen im Zeichen der Postmoderne subsumierbar schien. Ohne Zweifel steht Mario Vargas Llosa in der Tradition der Figur eines Intellektuellen in Lateinamerika, der mit seinem Schreiben gesellschaftliche Missstände anklagt, unabhängig davon, ob er sich nun zum Sozialismus kubanischer Prägung bekennt oder neoliberale Reformen ins Wirtschaftssystem Perus einzuführen gedenkt. Vielleicht könnte man ihn sogar der Traditionslinie des Intellektuellen Sartre'scher Prägung oder mehr noch des existenzialistisch-dissidenten Typus von Albert Camus zuordnen. Denn Camus' fundamentale Ideologie-Kritik hat Vargas Llosa zumindest zeitweise stark vertreten - nicht zuletzt daher rührt seine Kritik an sämtlichen ideologisch fundierten Systemen in Lateinamerika und teilweise auch weltweit, seien diese nun politisch rechter oder linker Natur. Dass eine solche Position selbst wiederum ideologisch ist, brauche ich Ihnen an dieser Stelle nicht zu sagen.

Von jeher nahm der peruanische Schriftsteller vom Bereich der Literatur aus Stellung zu politischen Fragen und Themen. Dies, so scheint mir, hat bislang eine vorwiegend postmoderne Rezeption seiner Texte verhindert. Wir können daraus den Schluss ziehen, dass die Postmoderne nicht zuletzt auch ein Phänomen der Rezeption ist, wobei bezüglich letzterer in zentraler Weise die jeweiligen Bilder oder Stereotypen eines bestimmten Schriftstellers oder einer bestimmten Schriftstellerin die Hauptrolle spielen. Selbst die Hinwendung zu Spiel und Mehrdeutigkeit wurde bei Vargas Llosa immer als deutlich politische Positionierung gelesen und im Sinne einer neoliberalen Ideologie verstanden.

So dürfen wir also festhalten: Stehen Vargas Llosas literarische Texte seit Mitte der siebziger Jahre auch in vielerlei Hinsicht im Zeichen der Postmoderne, so tut dies deren Rezeption gerade nicht. Dies ist ein erklärbares, aber letztlich doch recht kurioses Phänomen, wenn man an die Vertrautheit des peruanischen Autors mit den Massenkommunikationsmedien und an die enorme mediale Kompetenz denkt, welche seine Arbeiten in den Bereichen Literatur, Zeitungen 
und Zeitschriften, Film und Fernsehen auszeichnen. Um eine dem Autor liebe Metaphorik zu bemühen: Mario Vargas Llosa bewegt sich in den verschiedensten Medien wie ein Fisch im Wasser.

Gleichwohl zeigt sich gerade auch hier, dass Vargas Llosa die unterschiedlichsten Medien als mediengerechter Superstar keineswegs nur als postmoderne Klaviatur benutzt, sondern sehr wohl Formen der Selbstdarstellung und Einflussnahme präsentiert, die sich an einem eher als klassisch oder traditionell zu nennenden Bild des Intellektuellen orientieren. Damit wird auch anhand der Figur des peruanischen Schriftstellers deutlich, dass die Grenzen des Spiels und die Grenzen der Postmoderne nicht zuletzt von der jeweiligen gesellschaftlichen Situation des Landes oder der „Area“ abhängen, von der aus oder für die er als Autor schreibt. Daran hat auch die spanische Staatsangehörigkeit nichts Grundlegendes geändert. Nach dem Argentinier Jorge Luis Borges und dem Mexikaner Octavio Paz, die zu bevorzugten Zielscheiben linker Kritik wurden, zählte Mario Vargas Llosa über lange Jahrzehnte ebenfalls zu diesem Club. Doch seit dem Jahrzehnt nach seiner erfolglosen Präsidentschaftskandidatur ist es diesbezüglich um den Peruaner ruhiger geworden. Vielleicht nimmt man auch die politischen Einlassungen nicht mehr ganz so ernst, die er immer noch tätigt; seine Stärken jedenfalls, davon bin ich fest überzeugt, liegen eindeutig nicht auf dem Gebiet der Politik und noch nicht einmal auf dem Gebiet intellektuellen Engagements, sondern auf jenem seiner genuinen Leidenschaft - der Literatur.

Wir haben gesehen, dass Vargas Llosa die Diegesen seiner Romane zunächst von Lima und später Peru auf ganz Lateinamerika ausweitete und in einem weiteren Schritt weltumspannende Diegesen entwarf, denen seine Protagonisten zu folgen hatten. Ein gutes Beispiel dafür ist sein 2006 erschienener Roman Travesuras de la niña mala. Ich möchte Ihnen nun gerne noch den Autor als Literaturnobelpreisträger vorstellen und dafür einen Roman heranziehen, der vielleicht wie kaum ein anderer nicht nur die Kritik überzeugte - was wohl auch mitentscheidend für die Vergabe des Nobelpreises war -, sondern sich in eine aus meiner Sicht wichtige literarhistorische Entwicklung einschrieb, welche die Literaturen nach der Postmoderne auszeichnet. Dies bedeutet nicht, dass wir es auf inhaltlicher Ebene mit einem Thema oder auf struktureller Ebene mit einer Anlage zu tun hätten, welche sich erst in den vergangenen Jahren herausgebildet hätten. Doch die Grundstrukturen einer Archipelisierung, welche bis in die kartographisch-literarischen Isolarien des ausgehenden Mittelalters und der beginnenden Neuzeit zurückgehen und auf die wir in dieser Vorlesung bereits mehrfach, etwa bei José Lezama Lima oder João Guimarães Rosa, gestoßen waren, zeigen eine fundamentale Entwicklung an, die mit den Begrifflichkeiten der Postmoderne in keiner Weise mehr zu fassen ist. 
In der erwähnten sukzessiven Ausweitung der Diegesen von Vargas Llosas Romanen und Erzähltexten kommt zweifellos seinem 2010 - im Jahr seiner Stockholmer Auszeichnung - veröffentlichten Roman El sueño del celta ${ }^{17}$ eine besondere Bedeutung zu. Denn in ihm werden in einer sehr bewusst transareal angelegten Romandiegese Europa, Afrika und Amerika so miteinander verbunden, dass die drei Kontinente nicht voneinander getrennt gedacht werden können: Sie sind Bestandteile eines interdependenten Systems, dessen Herrschaftswissen freilich sehr ungleich verteilt ist. Was aber haben diese drei Areas im Fin de siècle des 19. Jahrhunderts vor Ausbruch des Ersten Weltkriegs miteinander $\mathrm{zu}$ tun?

Bereits in der gelungenen, von Pep Carrió entworfenen Umschlaggestaltung des Romans wird in den Umrissen des Kopfes von Roger Casement - dem Protagonisten dieser Geschichte - eine Weltkarte sichtbar, auf der die Orte dieses in der dritten Phase beschleunigter Globalisierung angesiedelten Geschehens wie Inseln erscheinen, welche durch Blutstropfen miteinander verbunden sind. $\mathrm{Ob}$ der peruanische Autor bei dieser Umschlaggestaltung mitwirkte, kann ich leider nicht sagen; zweifellos aber liefert diese visuelle Umsetzung einen wichtigen, wohl entscheidenden Schlüssel für das Verständnis des gesamten Romans. Die historische Figur des 1864 in der Nähe von Dublin geborenen und 1916 in London wegen Hochverrats hingerichteten Roger Casement verbindet dabei seine beiden so asymmetrischen ,Herkunftsinseln“ Irland und England mit den Schauplätzen jener extremen kolonialen und neokolonialen Ausbeutung, der zum damaligen Zeitpunkt der Kongo und das Gebiet des Putumayo im peruanischen Amazonastiefland ausgeliefert war. Wieder also ist letzteres einer der Hauptschauplätze innerhalb des die Alte mit der Neuen Welt verbindenden diegetischen Konstrukts, in welchem koloniale und postkoloniale Abhängigkeiten schonungslos aufgedeckt und mit ihren Profiteuren verbunden werden - den ,sauberen', bisweilen feinsinnigen Ausbeutern in Großbritannien.

Aber wieso spreche ich eigentlich von Archipelen? Wieso sollten wir den afrikanischen Kongo und das peruanische Amazonastiefland als Inseln betrachten? Die riesigen Ströme des Kongo und des Amazonas verweisen zwar durchaus auf die Tatsache, dass es sich hier keineswegs um Inseln im geographischen Sinne, sondern um Teile riesiger Kontinente handelt. Doch wird im Verlauf des von Vargas Llosa klug - wenn auch mit mancherlei Wiederholungen - orchestrierten Geschehens deutlich, dass wir es mit Inseln in einem globalen, weltwirtschaftlichen Sinne zu tun haben. Diese kontinentalen Inseln aber befinden sich - ganz so wie die geographische Insel Irland gegenüber England - in einer Situation

17 Vargas Llosa, Mario: El sueño del celta. México: Santillana - Alfaguara 2010. 


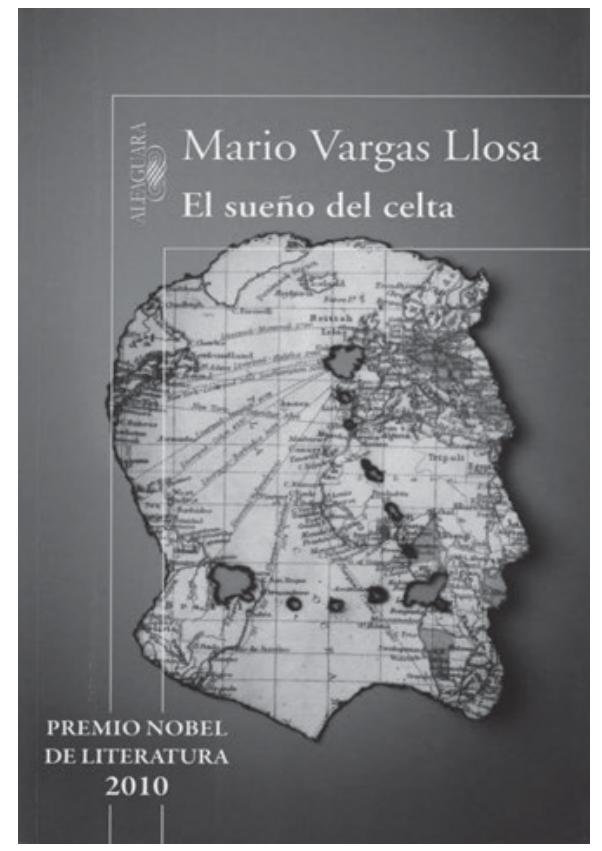

Abb. 126: Cover von Mario Vargas Llosas El sueño del celta, 2010.

extremer Unfreiheit und Abhängigkeit von jenen Zentren des Welthandels und der Weltpolitik, welche den Globalisierungsschub im letzten Drittel des 19. Jahrhunderts rücksichtslos vorantreiben. Dass Vargas Llosa seine Archipelgeschichte gerade während dieses Zeitraums, während dieses wichtigen Schubs einer noch ein letztes Mal unter europäischer Vorherrschaft stehenden Globalisierung angesiedelt hat, dürfte an sich schon als eine Meisterleistung des peruanischen Schriftstellers angesehen werden. Denn in seiner Romandiegese ist die transareale Archipel-Situation mit den Verzahnungen und Übergängen kolonialer und postkolonialer Abhängigkeit eindrucksvoll verknüpft.

Auch die zentrale Gestalt von El sueño del celta ist mit großem Gespür für historische Schlüsselmomente gewählt. In der Figur des hochdekorierten und in den Adelsstand erhobenen britischen Diplomaten und später gegen England rebellierenden irischen Nationalhelden Roger Casement selbst kulminieren immer wieder gleichsam transarchipelisch verschiedene Landschaften, Asymmetrien und Formen der Ausbeutung, die den Kongo, das Gebiet am oberen Putumayo und schließlich auch die britische Kolonie Irland über all ihre Differenzen hinweg miteinander verbinden. Denn stehen letztlich hinter allen politischen und wirtschaftlichen Aktionen nicht dieselben Interessen, dieselben Kräfte, dieselben Mächte? Und ist - wie es im Roman wiederholt heißt - der Kongo nicht überall? 
Roger fühlte sich in Raum und Zeit an den Kongo transportiert. Dieselben Menschen, dieselbe Verachtung der Wahrheit. Der einzige Unterschied bestand darin, dass Zumaeta auf Spanisch sprach und die belgischen Beamten auf Französisch. Sie verleugneten das Augenscheinliche mit derselben Leichtigkeit, weil sie jeweils daran glaubten, dass Kautschuk zu sammeln und Geld zu verdienen ein Ideal der Christen war, das die schlimmsten Missetaten gegen diese Heiden rechtfertigte, welche selbstverständlich immer Menschenfresser und Mörder ihrer eigenen Kinder waren. ${ }^{18}$

Die christlichen Ausbeuter und Mörder leugnen im Namen ihrer ,Werte‘ das Evidente. Der kolonialistisch-europäische Diskurs, der die schlimmsten Gräueltaten rechtfertigt, hat längst alles überwuchert und ist zur Selbstverständlichkeit, zur zweiten Natur der christlich ,Zivilisierten' geworden. Erst aus einem tieferen, im Sinne Wilhelm Diltheys ,durcherlebten ${ }^{19}$ Verständnis der kolonialen und neokolonialen Situationen in Afrika und Amerika erwächst dem leidenschaftlich für seine Ideale der Menschlichkeit kämpfenden britischen Diplomaten nicht nur eine Einsicht in die menschenverachtende Rücksichtslosigkeit der sich als so ,zivilisiert ${ }^{*}$ in Szene setzenden ,Mutterländer‘. Er erkennt auch die Tatsache, dass seine eigene irische Heimat denselben Prinzipien britischer Machtpolitik unterworfen ist. Irlands Situation wird für Roger Casement erst im Lichte der Rohkautschukgewinnung am Putumayo und am Kongo neu lesbar, schreibbar, erlebbar - und damit transformierbar. Das weltumspannende System des angelsächsischen Kolonialismus, das Weltwirtschaftssystem des British Empire gilt auch vor der eigenen Haustür auf der grünen Insel mit derselben Brutalität und Selbstverständlichkeit.

Mit Blick auf Roger Casement ist El sueño del celta ein Bildungsroman. Denn nur aus einer weltweiten Perspektive wird sich der Romanheld Stück für Stück darüber bewusst, dass Irland letztlich nichts anderes als eine Kolonie im Dienst britischen Kapitals ist - nicht anders als die gut getarnten Mechanismen der Peruvian Amazon Company. Letztere machen die Reichen reicher und die Armen ärmer, bis Casement - wie schon in seinem Bericht über die belgische Ausplünderung des Kongo - Öffentlichkeit herstellt und die ganze Unmenschlichkeit aufdeckt, auf welcher die Aktiengewinne dieses untadeligen Unternehmens an der Londoner Börse wirklich beruhen. Hatte er nicht ,grausame Verbrechen gegen primitive Völker und indigene Gemeinschaften auf zwei Kontinenten“ ${ }^{\text {20 }}$ erforscht

18 Vargas Llosa, Mario: El sueño del celta, S. 174.

19 Vgl. hierzu Dilthey, Wilhelm: Goethe und die dichterische Phantasie. In (ders.): Das Erlebnis und die Dichtung. Lessing - Goethe - Novalis - Hölderlin. Göttingen: Vandenhoeck \& Ruprecht ${ }^{16} 1985$, S. 139.

20 Ebda., S. 194: „crímenes atroces contra pueblos primitivos y comunidades indígenas de dos continentes.“ 
und auf diese Weise die Spielregeln in jener Phase beschleunigter Globalisierung erkannt, die bis zum Ausbruch des Ersten Weltkriegs galten, jenes schmutzigen interessegeleiteten Krieges, unter dessen günstigen Bedingungen er selbst das Schicksal Irlands in einer Allianz mit Berlin gegen London zu beeinflussen suchte? Hatte er nicht begriffen, dass sich hinter den feinen Manieren und zuvorkommenden Höflichkeiten menschenverachtendes Kalkül und eine Ausbeutermentalität verbargen, welche nichts, was sie einmal in Händen hielten, je wieder aus ihren Klauen lassen wollten?

Der gesamte Aufbau des Romans gliedert sich in die Kapitel „El Congo“, „La Amazonía“, „Irlanda“ und einen nachfolgenden Epilog. Er lässt von Beginn an keinen Zweifel daran, dass sich die Tropengebiete Afrikas und Amerikas trotz ihrer sehr unterschiedlichen politischen Situation - auf der einen Seite eine belgische Kolonie, auf der anderen der wirtschaftlich abhängige und korrupte peruanische Nationalstaat - in einer strukturellen Analogie befanden. Denn sie unterlagen ja den Rahmenbedingungen einer im Wettlauf der Mächte um die letzten zu verteilenden Kolonien gezielt beschleunigten Globalisierung, wobei sie - ganz wie das England so nahe Irland abhängigen Inseln gleich - mit ihren Machtzentren in Europa verbunden und deren Interessen gnadenlos unterworfen sind. Irland, Putumayo und Amazonas, der afrikanische Kongo: Galt für alle nicht dasselbe Weltwirtschaftssystem, das auf Ausbeutung beruhte und auch vor schrecklichsten Verbrechen nicht zurückschreckte?

Entscheidend in diesem globalen Wettlauf um Profite und Macht sind jeweils möglichst billig einsetzbare Arbeitskräfte, ohne deren Verfügbarkeit die angestrebte Gewinnmaximierung der die wirtschaftliche Globalisierung vorantreibenden Konzerne niemals möglich wäre. Ob die Ausbeutung dieser Arbeitskräfte noch auf Sklaverei, den billigen Händen der „Coolies“ oder neueren, noch raffinierteren Formen einer „Second Slavery“ beruhte, ${ }^{21}$ war im Grunde gleichbedeutend. Unter dem Vorwand einer Missionierung und Zivilisierung werden - zeitgleich zu den Deportationen von Arbeitssklaven im pazifischen Raum - ganze Völker in die als Lohnarbeit getarnte Versklavung oder den Tod getrieben, ein Prozess höchster Brutalität, den El sueño del celta in allen Details menschlicher Grausamkeit nachzuzeichnen und mehr noch sinnlich nachvollziehbar zu gestalten sucht. Auspeitschung, Verstümmelung, Folter und Mord wie schon im dominikanischen Diktatorenroman La fiesta del chivo aus dem Jahr 2000 ist das Arsenal an Grausamkeiten und Gewalttaten schier unerschöpflich.,

21 Vgl. hierzu Zeuske, Michael: Handbuch Geschichte der Sklaverei. Eine Globalgeschichte von den Anfängen bis zur Gegenwart. Zweite, überarbeitete und erweiterte Auflage. 2 Bände. Berlin Boston: Walter de Gruyter 2019. 
das der peruanische Autor vor den Augen seines Helden (und seiner Leserschaft) entfaltet.

Die Handlung ist eingebettet in eine global expandierende britische Wirtschaft, welche im harten Konkurrenzkampf mit anderen europäischen Ökonomien steht. Dabei ist es kein Zufall, dass dieser Roman, der wie stets bei Vargas Llosa auf Feldforschungen des Schriftstellers vor Ort beruht, die über ein Jahrhundert zurückliegende Globalisierungsphase aus einer Perspektive betrachtet, die ohne das Erleben der im Jahr 2010 noch fortgesetzten Phase beschleunigter Globalisierung undenkbar wäre. Mag der in seiner Präsidentschaftskandidatur in Peru knapp an dem späteren Diktator Fujimori gescheiterte Autor in seinen politischen Überzeugungen auch noch so sehr ein dem Neoliberalismus huldigender Schriftsteller sein: Sein Roman präsentiert einer nach dem Literaturnobelpreis mehr denn je weltweiten Leserschaft die ganze Wucht und Zerstörungskraft einer wirtschaftlichen, politischen, religiösen und kulturellen Expansion. Sie schuf einen Grad an internationaler Verflechtung und Abhängigkeit, wie er erst in den sechziger Jahren des 20. Jahrhunderts wieder erreicht werden sollte. El sueño del celta impliziert - jenseits von Vargas Llosas nicht immer glücklichen politischen Statements, die sich nie auf der Höhe seines literarischen Schaffens befinden auch eine Stellungnahme gegenüber all jenen Kräften, welche aktuelle ökonomische Globalisierungstendenzen vorantreiben, koste es, was es wolle. Denn diese Kosten sind höchst ungleich verteilt.

Eine Globalisierungsphase baut dabei auf einer anderen, früheren auf und die Strukturen und Asymmetrien, welche die erste Phase beschleunigter Globalisierung prägten, pausen sich noch in veränderter Form in der zurückliegenden vierten Phase durch. Es ist daher nicht von anekdotischer, sondern von struktureller Bedeutung, dass sich auch im Roman selbst verschiedene Phasen beschleunigter Globalisierung wechselseitig beleuchten und in ihren Kontinuitäten hinterfragen. Dies erfolgt schon an einer frühen Stelle des Romanverlaufs, als der Protagonist noch an die zivilisatorische Mission der Europäer glaubt und für die Sanford Exploring Expedition just an einem Ort arbeitet, zu dem ,vier Jahrhunderte zuvor die Karavelle des Diego Cao“22 vorgestoßen war. Der Rückblick auf die erste Phase beschleunigter Globalisierung ist in dieser Passage evident.

Doch ausgerechnet dort, wo der portugiesische Seefahrer einst auf einem Felsen seinen Namen - der damals noch lesbar war - verewigt hatte, beginnt nun eine deutsche Ingenieursfirma mit dem Aufbau einer Stadt für europäische Kolonialbeamte, deren Häuser aus europäischem Holz hier zum ausschließlichen Nutzen europäischer Konzerne errichtet werden. Man fühlt sich an das imperiale

22 Vargas Llosa, Mario: El sueño del celta, S. 54. 
Gebaren der gerade erst beendeten Phase beschleunigter Globalisierung erinnert, mit welchem die Sendboten US-amerikanischer oder europäischer Konzerne in Afrika oder Südostasien auftreten. Im Roman des peruanischen Autors wird mit Blick auf die dritte Phase deutlich, dass das neu gegründete Deutsche Reich verzweifelt Anschluss an die großen Kolonialmächte zu finden suchte. Bismarcks Schatten ist nicht nur in Europa, sondern auch in Afrika, Amerika und Ozeanien allgegenwärtig, auch wenn das Kaiserreich - anders als die USA - nicht vor 1914 in die erste Reihe expandierender Mächte vorzudringen vermochte und seine imperiale Phase glücklicherweise schon bald wieder zu Ende war. Freilich steht kaum zu erwarten, dass sich das ehemalige British Empire jemals für die anderen Völkern angetanen Gräueltaten auch nur entschuldigen wird. Doch zurück zu unserem Roman aus der Feder Vargas Llosas!

Die wiederholte Einbeziehung der ersten, der iberischen - und in Afrika vor allem portugiesischen - Phase beschleunigter Globalisierung ${ }^{23}$ lässt keinen Zweifel daran aufkommen, dass El sueño del celta die Prozesse der Globalisierung als Phänomen „de longue durée,“ als sich über mehrere Jahrhunderte erstreckende Entwicklung, zu begreifen und anschaulich zu machen bemüht ist. Die Bezeichnung Roger Casements als „el Bartolomé de las Casas británico“, ${ }^{24}$ als großer Freund indigener Völkerschaften seines Jahrhunderts - ein Satz, der dem Schriftsteller Joseph Conrad zugeschrieben wird -, stellt nicht nur mit einem Augenzwinkern aus der Blickrichtung der vierten Phase beschleunigter Globalisierung eine direkte Beziehung zwischen der ersten und der dritten Phase her. Er macht nämlich zugleich deutlich, dass über die Verbindungen zwischen Afrika und Amerika hinaus längst die gesamte Tropenwelt zum Bewegungsraum europäischer Interessen geworden ist. ${ }^{25}$ Auf der Hauptinsel des Empire liefen im Norden Europas alle Fäden zusammen, mit deren Hilfe die kolonialen Inseln im globalen Süden - von Indien bis Ozeanien, von der Karibik bis Südafrika - kontrolliert und nach Belieben manövriert werden konnten. Diese Archipelstruktur war insulär geprägt und imperiale Ausdrucksform beherrschender ökonomischer und militärischer Macht im globalen Maßstab.

Aber was - so darf man sich bei all diesen nicht allein transarealen, sondern auch transhistorischen Verknüpfungen verschiedener Räumen und Zeiten der

23 Ein weiterer Verweis findet sich u.a. auf S. 73; weitere Hinweise passim.

24 Ebda., S. 74.

25 Zum kolonialen Bewegungsraum der Tropen vgl. Ette, Ottmar: Diskurse der Tropen - Tropen der Diskurse: Transarealer Raum und literarische Bewegungen zwischen den Wendekreisen. In: Hallet, Wolfgang / Neumann, Birgit (Hg.): Raum und Bewegung in der Literatur. Die Literaturwissenschaften und der Spatial Turn. Bielefeld: transcript Verlag 2009, S. 139-165. 
Globalisierung fragen - hat eigentlich die (europäische) Menschheit aus all diesen Katastrophen gelernt, aus Genozid und Zerstörung, die nicht zuletzt aus Glaubenseifer oder Profitgier über die (gesamte) Erdbevölkerung gebracht wurden? Gibt es ein Umdenken bezüglich der Abhängigkeitsverhältnisse globalen Maßstabs bei denen, die über die Macht dazu verfügen?

Mario Vargas Llosas sehr bewusst transareal angelegter Roman gibt auf diese von ihm nahegelegten Fragen keine einfachen Antworten. Er führt in erster Linie einen Lernprozess vor Augen, welcher über die Figur Roger Casement ebenso seine Leserschaft erfasst. Denn auch der britische Staatsbürger sieht sich im Kongo immer wieder bohrenden Fragen ausgesetzt, auf die er in den ersten Jahren keine schlüssigen Antworten zu geben vermag: „Waren denn die Interessen des Imperiums nicht wichtiger als die lauten Klagen einiger halbnackter Wilder, die Katzen und Schlangen anbeteten und andere Menschen verspeisten? “26

Von Beginn an war in der ,Begegnung' zwischen den ,Wilden` und den ,Zivilisierten' die ideologische Rechtfertigung einer Unterwerfung und Ausbeutung jener kaum menschenähnlichen ,Wilden' ungeheuer effizient gewesen.$^{27}$ Schließlich galt es, die hehren Ziele des jeweiligen ,zivilisierten' Imperiums und des von ihm jeweils vertretenen Glaubens zu verteidigen. Wie Fray Bartolomé de las Casas' Beispiel zeigt, war es ungeheuer schwer, sich diesen Ideologien und Verstrickungen zu entziehen und nicht die einen Indigenen gegen die anderen auszuspielen, also etwa die indianische Bevölkerung durch die Einführung schwarzer Sklaven zu ,schützen'. Durfte man denn - so Roger Casement einige Jahrhunderte fortgesetzter Ausbeutung später - nicht als Europäer hoffen, dass der zivilisatorische Fortschritt aller verwerflichen Übergriffe zum Trotz nicht letztlich allen Menschen, auch den auf ihrem eigenen Kontinent wie Lasttiere misshandelten Afrikanern, nutzen würde?

Gleichwohl ist dem Iren klar geworden, dass sich seit der Eroberung Amerikas durch iberische Konquistadoren kaum etwas verändert hatte und dass die meisten Weißen - oder solche, die sich dafür hielten ${ }^{28}$ - die Indianer aus der Kategorie „Mensch“ noch immer exkludierten:

26 Vargas Llosa, Mario: El sueño del celta, S. 108: „¿No eran los intereses del Imperio más importantes que las quejas plañideras de unos salvajes semidesnudos que adoraban felinos y serpientes y eran antropófagos?“

27 Vgl. Bitterli, Urs: Die „Wilden“ und die „Zivilisierten“. Die europäisch-überseeische Begegnung. München: Deutscher Taschenbuch Verlag 1982.

28 So wurden die Iren in den USA bis zu Beginn des 20. Jahrhunderts kategorial nicht als Weiße betrachtet; vgl. zur Problematik dieser historisch höchst wandelbaren Kategorie Painter, Nell Irvin: The History of White People. New York - London: W. W. Norton 2010. 


\begin{abstract}
Für sie waren die Amazonas-Indianer im eigentlichen Sinne keine Menschen, sondern eine inferiore und verachtenswerte Form der Existenz, welche jener der Tiere näher stand als jener der Zivilisierten. Es war daher legitim, sie auszubeuten, sie auszupeitschen, sie zu entführen, sie an die Kautschukstätten zu verbringen oder sie, wenn sie Widerstand leisteten, wie einen Hund umzubringen, der die Tollwut verbreitet. ${ }^{29}$
\end{abstract}

Alles war gleich geblieben: Noch immer lastete die brutalste Form der Ausbeutung auf den ,Wilden', die man ungefragt und unbestraft in Sklaven verwandelte und deren Arbeitskraft man nach Belieben zum höheren Ruhm irgendeines Imperiums nutzte. Waren es überhaupt Menschen, die man da umbrachte? Und doch hatte sich zugleich etwas verändert. Denn es war möglich geworden, durch die Macht des Wortes, durch die Kraft offizieller Berichte eine Öffentlichkeit wachzurütteln, die - erst einmal in ihrem durchaus gewinnbringenden Schlaf gestört - zu reagieren und zu agieren in der Lage war. Diese schlafende Macht war gewaltig, wurde sie erst einmal geweckt und über die wahren Ziele ihrer Firmen, „Empresas“, Trusts und Konzerne aufgeklärt. Soll nicht im Jahre 2020 ein Gesetz den Bundestag passieren, das Kinderarbeit und Ausbeutung verbietet und halbwegs menschliche Mindeststandards in den Fabriken einführt, die für deutsche Konzerne produzieren? Doch die deutsche Wirtschaft wehrt sich, verweist auf Konzerne anderer Länder, beschönigt und verdeckt. Und es könnte sein, dass die deutsche Öffentlichkeit erneut mit dem Gedanken einschläft, dass es schon nicht so schlimm sein werde und dass westliche Konzerne freiwillig auf Kinderarbeit und Ausbeutung verzichten würden, dass schon alles gut werde ...

Roger Casement jedoch wusste ein gutes Jahrhundert zuvor, dass es galt, diese Öffentlichkeit im britischen Empire wachzurütteln und wachzuhalten, weil anders gegen die seit Jahrhunderten fortgesetzte und seit Jahrhunderten ökonomisch verschärfte Ausbeutung nicht anzukommen war. Immerhin war es nun eine weltweite Öffentlichkeit, die erreicht werden konnte, eine Öffentlichkeit, die bei allen scharfen Asymmetrien an der Wende vom 19. zum 20. Jahrhundert innerhalb gewisser Grenzen als eine entstehende Weltöffentlichkeit bezeichnet werden darf. Eine Informationsgesellschaft ${ }^{30}$ im zeitgenössischen Sinne der vierten Phase beschleunigter Globalisierung funktionierte gewiss noch nicht, und selbstverständlich gab es zwar transatlantische Kabelverbindungen, aber noch lange kein Internet, das im digitalen Maßstab gewaltige Informationsmengen weltweit ,in real time“ öffentlich und zugänglich machen konnte.

29 Vargas Llosa, Mario: El sueño del celta, S. 209.

30 Castells, Manuel: Das Informationszeitalter. Opladen: Leske \& Budrich 2001; sowie ders.: Communication power. Oxford - New York: Oxford University Press 2008. 
Und doch gab es zu Roger Casements Zeiten Möglichkeiten, das Räderwerk der Ausbeutung gleichsam vor Ort vorzuführen, an jenem noblen Firmensitz der Peruvian Amazon Company im Herzen des Welthandelszentrums London. Es sind Möglichkeiten, wie sie der Roman selbst auf wenigen Zeilen verdichtet aufzeigt:

\begin{abstract}
Roger war in den Büros der Peruvian Amazon Company in Salisbury House, E.C., im Finanzzentrum von London gewesen. Ein spektakulärer Ort war das, mit einer Landschaftsmalerei von Gainsborough an der Wand, mit Sekretärinnen in Uniform, mit Büros voller Teppichen, Ledersofas für die Besucher und einem Schwarm von Clerks mit ihren gestreiften Hosen, ihren schwarzen Westchen und weißen Hochkragenhemden nebst Krinolinekrawatten, die Berechnungen durchführten, Telegramme verschickten und erhielten, Lieferungen von duftendem Weichkautschuk in alle Industriestädte Europas verkauften und abkassierten. Und am anderen Ende der Welt, am Putumayo, die Huitotos, Ocaimas, Huinanes, Nonuyas, Andoques, Rezígaros und Boras, die Zug um Zug ausstarben, ohne dass jemand auch nur einen Finger gerührt hätte, um diesen Zustand zu verändern. ${ }^{31}$
\end{abstract}

Wir haben es in dieser Passage mit der Konfiguration eines literarischen WeltFraktals zu tun, insofern sich in diesem Gebäude der Peruvian Amazon Company wie in einem Brennspiegel eine ganze Welt verkörpert. Sie enthalt ebenso einen Schwarm rechtschaffener Büroangestellter und Sekretärinnen wie ganze Völkerschaften von Amazonasindianern, die auf den ersten Blick nichts miteinander zu tun haben, auf den zweiten aber in eine mörderische Asymmetrie verstrickt sind. Beide Seiten sind letztlich nur Anhängsel einer weltumspannenden kapitalistischen Struktur, die zum Wohle einiger weniger ganze Völkerschaften ausrottet. Auf wenigen Zeilen wird hier eine weltweite Interdependenz bei gleichzeitiger radikaler Asymmetrie der Machtverteilung innerhalb einer Situation vorgeführt, in der die modernen transatlantischen Kommunikationsmedien den Austausch von Informationen sicherstellen. Doch sie gehorchen einseitigen Interessenlagen, die weit über die Interessen jener Sekretärinnen und Büroangestellten hinausreichen, die als sichtbare „Uniformierte“ letztlich auf das verweisen, was zunächst unsichtbar bleibt. Gerade im unsichtbar Bleibenden werden jedoch auf diesen wenigen Zeilen die Machtstrukturen ästhetisch wirkungsvoll sichtbar gemacht. In dieser Passage zeigt sich die ganze Kraft der Literatur, uns nicht nur Menschen und Strukturen zu präsentieren, sondern uns deren lebenserfüllte Implikationen sinnlich nacherleben zu lassen.

Das Landschaftsgemälde des englischen Malers Thomas Gainsborough ist trefflich gewählt und vom peruanischen Autor vieldeutig eingesetzt. In ihm zeigt sich genau das, was nicht gezeigt wird, verbirgt sich das, was uns vor Augen geführt

31 Vargas Llosa, Mario: El sueño del celta, S. 220. 
wird. In dieser mit dem zeitgenössischen Dekor und der damaligen Mode wohlvertrauten Passage des historischen Romans kommt auch der Kunst eine bestimmte Funktion zu: jene einer ornamentalen, das symbolische Kapital ihrer Besitzer zugleich dokumentierenden und erhöhenden Rolle, die in ihrem Entwurf einer Landschaft zugleich all jene Landschaften verbirgt, für deren Wert und Würde sich niemand verbürgt. Gegen eine solche Kunst, für die hier Thomas Gainsboroughs Gemälde stellvertretend steht, rebellieren sowohl der Protagonist als auch der Roman selbst, versuchen sie doch, für ein Bewusstsein einzutreten, das man mit Alexander von Humboldt als komplexes Weltbewusstsein ${ }^{32}$ bezeichnen könnte. Dabei geht es nicht um eine kontinuierliche, ununterbrochene Fläche, die über die Welt ausgespannt wird, sondern um die Verbindung zwischen einzelnen Areas, welche miteinander und gegeneinander in eine asymmetrische Beziehung gebracht werden. Es geht um eine archipelische Situation.

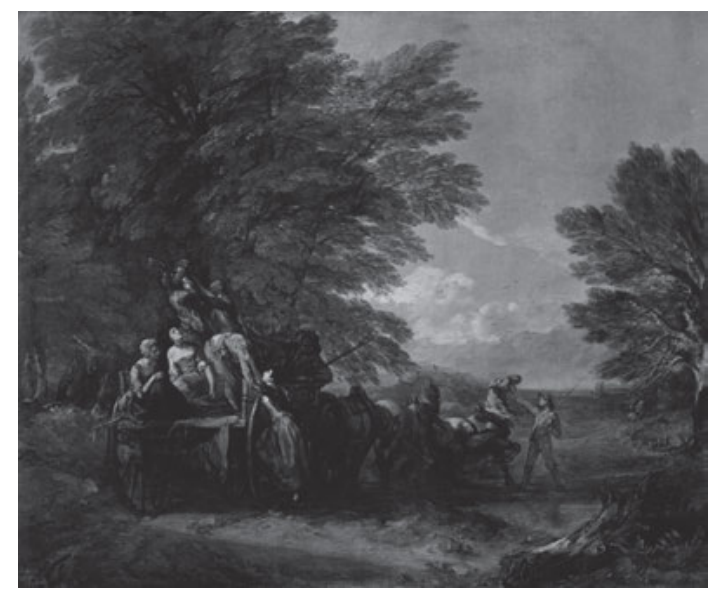

Abb. 127: Thomas Gainsborough: Der Erntewagen, Öl auf Leinwand, 1767.

Ohne an dieser Stelle auf die im gesamten Roman feststellbare hohe Frequenz des Lexems „Leben“ („vida“, „vivir“, „viviente“ usw.) eingehen zu können, sei doch betont, wie sehr in Vargas Llosas Roman eine immanente Poetik eingewoben ist, die der Kunst die Aufgabe zuweist, Komplexität und Widersprüchlichkeit des menschlichen Lebens im Experimentierraum ästhetisch nacherlebbar zu gestalten. Immer wieder hat der peruanische Autor mit seiner medialen Kompetenz gerade auch die Beziehungen zwischen Text und Bild, zwischen Literatur und

32 Vgl. Ette, Ottmar: Weltbewusstsein. Alexander von Humboldt und das unvollendete Projekt einer anderen Moderne. Mit einem Vorwort zur zweiten Auflage. Weilerswist: Velbrück Wissenschaft 2020. 
Malerei ins Zentrum seiner Romane gestellt - wie in seinem Flora Tristan und Paul Gauguin gewidmeten El paraíso en la otra esquina ${ }^{33}$ von 2003.

Die Einsicht Roger Casements, der zufolge „das Leben, das weitaus komplexer als alle Berechnungen ist“, ${ }^{34}$ sich jeglicher wissenschaftlichen Berechenbarkeit entzieht, wird zur Grundlage einer Handlungs- und Figurengestaltung, in der die literarische Gestalt Roger Casement selbst zum „lebendigen Beispiel dieser Zweideutigkeiten“355 gerät. In Casements politischen und biopolitischen, humanistischen und nationalistischen, erotischen und ökonomischen Positionen wird eindrucksvoll zur Anschauung gebracht, mit welcher Offenheit, Widersprüchlichkeit und Widerspenstigkeit sich das Leben im Dreieck von Finden, Erfinden und Erleben literarisch repräsentieren lässt. Denn wir finden unser Leben nicht einfach vor, wir erfinden es ständig auf andere Weise und verändern es dadurch, dass wir es leben, erleben und durcherleben. Zwischen diesen drei Polen bestimmt sich jegliche Kunst.

Aufgabe der Literatur ist es nicht, diese Ambiguitäten und Vieldeutigkeiten aufzulösen und in Berechenbarkeit zu überführen. Es geht vielmehr darum, Denkund Interpretationsmuster zu erproben und bereitzustellen, welche die Nacherlebbarkeit von Lebensprozessen anstreben, indem diese anhand literarischer (wenngleich bisweilen historischer) Figuren durchgespielt werden. Kunst und Literatur entfalten vor unseren Sinnen das Viellogische von Lebensvorgängen, die Polylogik und Polysemie von Lebensprozessen in all ihrer ästhetisch reflektierten Komplexität. Kaum eine andere literarische Figur könnte uns so wirkungsvoll wie Vargas Llosas Roger Casement dazu dienen, aus unserer gegenwärtigen Perspektive die Problematiken des Globalisierungsschubs an der Wende vom 19. zum 20. Jahrhundert so plastisch in ihren Widersprüchen aufzuzeigen und damit in ihrer transarealen Dynamik buchstäblich zu vergegenwärtigen. In seiner schillernden Gestalt, in deren Homosexualität sich die quer zu allen Normen verlaufenden Formen menschlicher Beziehungen verkörpern, bündeln sich erlebbar und nacherlebbar verschiedenste Isotopien, welche für diese dritte Phase beschleunigter Globalisierung maßgeblich sind.

Wollte man es paradox formulieren, so könnte man behaupten, dass Roger Casement gerade deshalb, weil er sich selbst „nunca de ninguna parte“36 fühlte, also nirgendwo zuhause war, sein Leben im Kampf für den Traum eines freien,

33 Vgl. hierzu das unter anderem diesem Roman gewidmete Kapitel in Ette, Ottmar: WeltFraktale. Wege durch die Literaturen der Welt. Stuttgart: J.B. Metzler Verlag 2017.

34 Vargas Llosa, Mario: el sueño del celta, S. 355: „la vida, más compleja que todos los cálculos.“ 35 Ebda., „ejemplo viviente de esas ambigüedades.“

36 Ebda., S. $374 \mathrm{f}$. 
unabhängigen Irlands verlieren musste. Das Irland dieses Traumes, dieses „sueño“, steht als ,seine“ Heimatinsel für all jene Inseln, die er in seinem Leben ohne festen Wohnsitz zu den seinen gemacht und für die er sein Leben riskiert hatte. Seine letzte Insel wird die Heterotopie seines Gefängnisses sein, in welchem er auf seinen Tod wartet, zu dem ihn ein Empire verurteilte, das damals nicht mit sich spaßen ließ. Als Wanderer zwischen den Welten - zwischen Irland und England, aber auch zwischen Europa, Afrika und Amerika - musste er ein sehr feines Gespür für das Schicksal all jener Völker besitzen, die am Ende der oben zitierten Passage nach der Schilderung des luxuriösen Firmensitzes der Peruvian Amazon Company in London kurz auftauchen. Sie erscheinen dort allein deshalb, um als deportierte, versklavte Lohnarbeiter und der Ausrottung preisgegebene Arbeitssklaven endgültig von der Geschichte verschlungen zu werden.

All dieser Menschen, die gefälschten Dokumenten entsprechend als Lohnarbeiter geführt und offiziell für ihre Arbeit bezahlt werden, scheint sich niemand in Europa oder anderswo annehmen zu wollen. Doch mag die offizielle Geschichte sie auch ausgeschlossen haben: El sueño del celta versucht, dieser historischen Exklusion in der zum Zeitpunkt der Abfassung des Romans aktuellen Globalisierungsphase eine Inklusion entgegenzusetzen, die sie zwar nicht in Subjekte ihrer eigenen Geschichte verwandelt, zumindest aber als von der Geschichte Misshandelte wieder in Erscheinung treten lässt. Mario Vargas Llosa gelingt es in diesem historischen Roman, Grundstrukturen einer längst vergangenen Globalisierungsphase sinnlich erlebbar zu machen und jene Archipel-Situation ästhetisch zu evozieren, die sich in ihren Diskontinuitäten deutlich von Ästhetiken im Zeichen der Postmoderne unterscheidet. Um diese neuesten Entwicklungen von Ästhetiken, welche durchaus noch in literarischen Beziehungen zur Postmoderne stehen, aber deutlich nach der Postmoderne angesiedelt sind, wird es in den abschließenden Sitzungen unserer Vorlesung gehen. 